\title{
A taxonomy for planning and designing smart mobility services
}

\author{
Guillermina Cledou $^{\mathrm{a}, *}$, Elsa Estevez ${ }^{\mathrm{b}}$, Luis Soares Barbosa ${ }^{\mathrm{a}}$

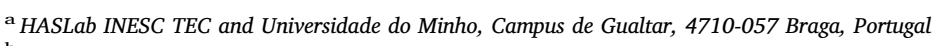 \\ ${ }^{\mathrm{b}}$ Institute for Computer Science and Engineering (UNS-Conicet), Department of Computer Science and Engineering, Universidad Nacional del Sur, San Andrés 800, Campus \\ Palihue, Bahía Blanca, Argentina
}

\section{A R T I C L E I N F O}

\section{Keywords:}

Smart cities

Smart mobility

Taxonomy

City transport

Digital services

Public value

\begin{abstract}
A B S T R A C T
The development of smart mobility initiatives requires specialized and contextualized policies addressing the needs and interests of many stakeholders involved. Since the development of such policies is challenging, there is a need to learn from the experience of many cities around the world offering efficient and successfully adopted smart mobility services. However, in practice, the information provided about such initiatives is shallow and unstructured. To address this issue, we study the state of the art in mobility services, reviewing scientific publications and 42 smart mobility services delivered by nine smart cities around the world, and we propose a taxonomy for planning and designing smart mobility services. The taxonomy provides a common vocabulary to discuss and share information about such services. It comprises eight dimensions: type of services, maturity level, users, applied technologies, delivery channels, benefits, beneficiaries, and common functionality. The contribution of the proposed taxonomy is to serve as a tool for guiding policy makers by identifying a spectrum of mobility services that can be provided, to whom, what technologies can be used to deliver them, and what is the delivered public value so to justify their implementation. In addition, the taxonomy can also assist researchers in further developing the domain. By identifying common functionality, it could also help Information Technology (IT) teams in building and maintaining smart mobility services. Finally, we further discuss usage scenarios of the taxonomy by policy makers, IT staff and researchers.
\end{abstract}

\section{Introduction}

By 2050 it is expected that $66 \%$ of the world population will reside in urban areas (United Nations, 2014). As the number of urban residents increases, local governments need to address serious sustainable and development challenges in various areas, including mobility. Mobility issues impact on citizens' quality of life and the overall sustainability of cities. For example, travel time shows a strong positive relationship with life satisfaction in smaller cities, but such relation is non-existent in large cities, mainly due to the costs of traffic congestion (Morris, 2015). Regarding sustainability, in the United States, transportation is responsible for $27 \%$ of the greenhouse gas emissions (U.S. Environmental Protection Agency, 2015), while in developing countries the transport sector is responsible for $80 \%$ of air pollution (UNEP, 2012). Globally, it is estimated that road transport consumes about $70 \%$ of the energy used in the world transport system and that only road passenger transport accounts for $50 \%$ of this energy consumption (Deutsche Gesellschaft für Internationale Zusammenarbeit, 2012). Additionally, as part of the Sustainable Developments Goals (SDGs), ${ }^{1}$
SDG11 refers to make cities more inclusive and sustainable. In particular, target 11.2 defines that by 2030 , governments should provide access to safe, affordable and sustainable transport systems for all. Moreover, from the research perspective, according to (Janowski, 2016), $87 \%$ of the 169 SDGs targets require digital government capacity at the highest contextualization stage (Janowski, 2015), meaning digital public services focused on a specific policy issue - like transport, or on given contextual conditions. Such statement is related with the results of the state of practice presented in this paper, showing the efforts of several local governments developing smart services focused on mobility and transport-related issues. Thus, we conclude the relevance and need faced by local governments to make a strategic use of digital technologies to achieve the SDG11, particularly target 11.2 related to transport systems.

In recent years, there have been many efforts worldwide to develop smart city initiatives through the various dimensions of a smart city (Giffinger et al., 2007): smart economy, smart environment, smart governance, smart living, smart people, and smart mobility. Related to our research interest, smart mobility focuses on the use of integrated

\footnotetext{
* Corresponding author.

E-mail addresses: mgc@inesctec.pt (G. Cledou), ece@cs.uns.edu.ar (E. Estevez), 1sb@di.uminho.pt (L. Soares Barbosa).

${ }^{1}$ http://www.un.org/sustainabledevelopment/cities/.
} 
ICT infrastructures, sustainable transport systems and logistics to support better urban traffic and mobility. Some examples of smart mobility services include the provision of real time and multi-modal public transport information, and traffic light optimization to attend to realtime traffic demand. In addition to their relevance, the planning and development of smart mobility services is challenging. One of the challenges is that digitization policies and strategies need to carefully consider the interests and needs of the many stakeholders involved (government, citizens, commuters, transport providers, etc.), such that possible (un)expected negative effects to some group of stakeholders are minimized.

Existing solutions, examples of good practices, have been implemented in smart cities, offering a catalogue of initiatives from which governments can learn and consider for adoption in their own local context. However, the information available of such initiatives is shallow, unstructured, and not properly maintained. In addition, given the lack of information- and experience-sharing, each local government develops its own ad-hoc solutions to deliver mobility services, ignoring that in practice many of such services share common functionality and thus, could be built using reusable components simplifying development processes and significantly reducing costs.

With the aim of addressing the lack of structured information and deepening the knowledge in smart mobility services, we study the state of the art in the provision of such services, reviewing scientific publications and 42 smart mobility services delivered by nine smart cities around the world. Our research work is guided by three research questions: RQ1) What kind of smart mobility services are delivered in the context of smart cities?, RQ2) How such services are delivered?, and RQ3) What kind of public value is delivered by smart mobility services and to whom? Based on the analysis and findings, we propose a taxonomy for planning and designing smart mobility services. The taxonomy comprises 8 dimensions: type of services, maturity level, users, applied technologies, delivery channels, benefits, beneficiaries, and common functionality. The structuring nature of taxonomies enables to identify and define common concepts for each of the dimensions, providing a common vocabulary to discuss and share information about smart mobility services. In addition, it provides a specialized and contextualized tool for policy makers involved in the development of smart mobility initiatives. In particular, the concrete dimensions identify the spectrum of mobility services that can be provided, to whom they are provided, what technologies can be used to deliver them, and the public value that is delivered through each kind of service. Identifying common functionality can also help software engineers and IT staff to implement smart mobility services through reusable components, ready to be configured and integrated into software applications. Finally, this article also provides usage scenarios of the taxonomy by policy makers and government officials responsible for enhancing smart mobility systems, by IT staff responsible for building and maintaining integrated smart mobility systems, and by researchers interested in further developing the area.

The rest of this article is structured as follows. Section 2 provides some background on taxonomies. Section 3 presents the research methodology. Section 4 describes the state of the art on smart mobility services; while Section 5 introduces the taxonomy, and Sections 6 and 7 discuss the validation and maintainability of the proposed taxonomy, respectively. Section 8 highlights potential users and usage scenarios of the taxonomy and discusses some lessons learnt from this work as well as the identified limitations. Finally, Section 9 summarizes the conclusions.

\section{Background}

\subsection{Building taxonomies}

Taxonomy is the science of classification. It structures information of a given domain into groups and lays out their relations, providing a conceptual framework for discussion, analysis, and information retrieval (Bruno \& Richmond, 2003). We use a taxonomy since we are merely concerned with the classification of concepts, although it can be later evolved into an ontology with richer relations and characterization of the concepts. Below we discuss some key aspects of taxonomy structure and development.

\subsubsection{Taxonomy structure}

The most common types of relations between concepts are hierarchies, trees, and faceted (Kwasnik, 1999). We focus on the faceted structure due to its many advantages. The approach considers that there are multiple perspectives or facets to model a concept. Main advantages include: 1) hospitability - it does not require a complete knowledge of the domain. This is attractive for emerging or changing domains, as the smart mobility domain, which is continuously evolving due to advances in technology and changing needs; 2) flexible searches - facilitates recovering information in multiple ways; e.g., benefits delivered by type of service; 3 ) greater expressiveness - each facet can use the structure that best suits the knowledge that it represents; and 4) flexibility - each concept can accommodate multiple perspectives. As a limitation, facets do not explicitly express meaningful relations between concepts.

\subsubsection{Taxonomy development}

The categories of a taxonomy are constructed following an iterative process. In each iteration a development approach is selected and at the end of the process it is analysed if categories are properly defined, need to be merged, or if new ones can be identified (Nickerson, Varshney, \& Muntermann, 2012). There are three well known development approaches (Bailey, 1994): Conceptual, Empirical, and Operational. The last one is a combination of the previous two and is the most commonly used in practice. An Operational approach can be either Conceptual to Empirical, where categories are first conceptualized following a deductive process, based on theory, domain knowledge, or experience, and then empirical cases are identified for each concept; or Empirical to Conceptual, where a series of empirical cases are first identified, analysed and grouped based on recognized similarities, and then conceptual labels are formulated for them. In addition, various methodologies and best practices exist for taxonomy development. We identify three that are generic enough to easily adapt to our domain: 1) [BR] (Bruno \& Richmond, 2003), and 2) [CJ] (Cisco \& Jackson, 2005) - both focusing on organizational aspects; and 3) [NVM] (Nickerson et al., 2012) - focusing on information systems. We believe that the three methodologies complement each other, and as such, we propose a methodology combining guidance and steps from all of them. In particular, [NVM] recognizes the need for an iterative development process and provides guidance for selecting a development strategy, the criteria to develop a useful taxonomy and how to use such criteria to evaluate the taxonomy; [BR] recognizes the need of a data collection process; and $[\mathrm{BR}]$ and $[\mathrm{CJ}]$ distinguish different taxonomy structures and provide guidance for maintaining the taxonomy. The proposed methodology is described in Section 3.

\subsection{Related work}

Some taxonomies exist in the literature covering smart city concepts, for instance: a taxonomy of application domains for smart cities, including transport and mobility domain that is further classified into city logistics, info-mobility, and people mobility (Neirotti, De Marco, Cagliano, Mangano, \& Scorrano, 2014); a taxonomy to classify smart city projects comprising the description of the project, the business model, and the purpose (Perboli, De Marco, Perfetti, \& Marone, 2014); and a taxonomy of technologies for smart cities (Yaqoob et al., 2017). Recently, a taxonomy of smart mobility has been proposed (Benevolo, Dameri, \& Auria, 2016). Such a taxonomy intersects with the one proposed in this article in the types of services and benefits dimensions, and in some values identified for such dimensions. We believe that the 


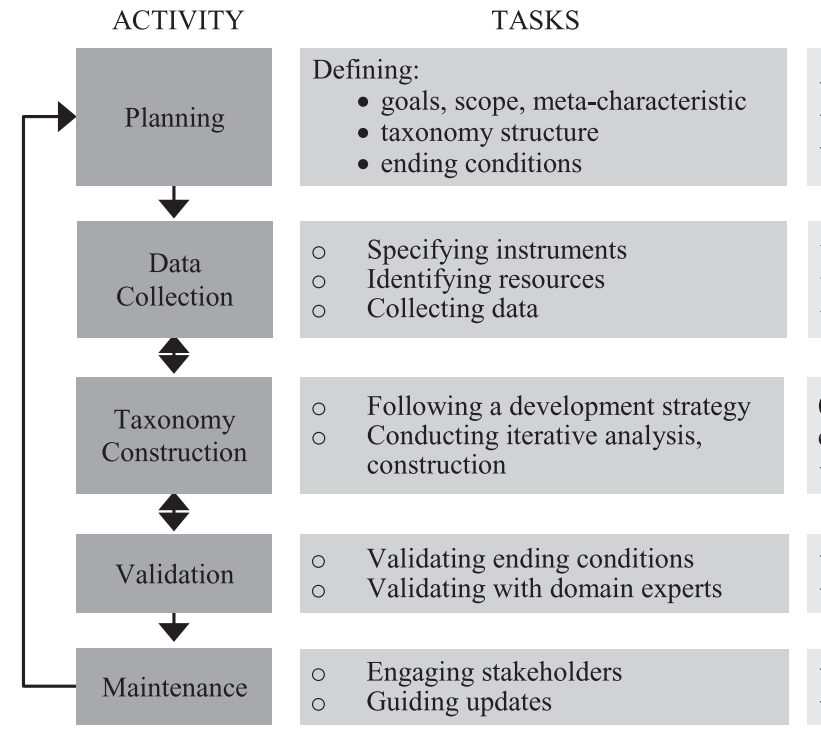

RESULTS

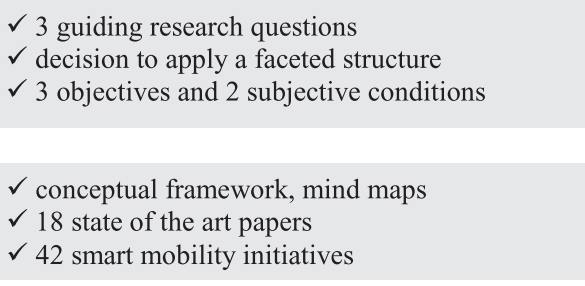

(strategies applied: conceptual-to-empirical, empirical-to-conceptual)

$\checkmark 8$ final dimensions

$\checkmark$ ending conditions met

$\checkmark 2$ focus groups conducted with domains experts

$\checkmark$ guidance for researchers

$\checkmark$ guidance for policy-makers

Fig. 1. Methodology for taxonomy development.

taxonomy proposed here provides a wider view of smart mobility services by considering other dimensions related to service development. In addition, main differences between both taxonomies include: we recognize benefits for all dimensions of a smart city, while Benevolo et al. focus on benefits for smart mobility; we focus in services highly relying on ICT, while Benevolo et al. consider a broader range of solutions, such as vehicles depending on sustainable fuels and policy actions; and we develop the taxonomy based on the state of art assessed from literature review and 42 initiatives from smart cities around the world, while Benevolo et al. focus on economic papers regarding policies and technologies for urban and smart mobility, especially in Europe.

\section{Methodology}

The proposed methodology for taxonomy development comprises five steps: 1) Planning, 2) Data Collection, 3) Taxonomy Construction, 4) Validation, and 5) Maintenance. A comprehensive view of the methodology is depicted in Fig. 1, including the five main activities, tasks involved in each activity and some results obtained. The activities conducted and decisions made in each step are described in the following sections.

\subsection{Planning}

This step provides the foundations to develop the taxonomy. It defines the goals and scope of the taxonomy, meta-characteristics, ending conditions, and structure of the taxonomy.

\subsubsection{Goals, scope, and meta-characteristics}

The goal is to structure knowledge related to smart mobility services. The scope of the taxonomy is limited to smart mobility services, in particular, software intensive services, with limited attention given to services depending mainly on non-software technologies, such as electric vehicles. The research questions formulated in Section 1 serve as the meta-characteristics of the taxonomy, i.e., they represent the most comprehensive characteristics that will serve to determine the features of the taxonomy. The main dimensions of the taxonomy should be a logical consequence of these meta-characteristics.

\subsubsection{Taxonomy structure}

We selected a faceted structure due to its many advantages as discussed in Section 2, and due to the different aspects, or facets, explored by the meta-characteristics.

\subsubsection{Ending conditions}

We selected the following objective and subjective ending conditions, based on [NVM]. Objective conditions: 1) no dimensions or characteristics were merged or split in the last iteration; 2) no new dimensions or characteristics were added in the last iteration; and 3) each dimension and characteristic is unique and not repeated. Subjective conditions: 1 ) the number of dimensions allows the taxonomy to be meaningful without being unwieldy or overwhelming; and 2) dimensions and characteristics can be easily added.

\subsection{Data collection}

This step comprises the identification of resources and instruments to collect data, and the actual collection of data. We divided the data collection process into state of research, to collect data from scientific publications on smart mobility solutions, and state of practice, to collect data about mobility services delivered in the context of smart cities.

\subsubsection{State of research}

We selected Scopus ${ }^{2}$ as the main source due to its coverage of journal publications and publications on hard sciences, e.g., computer science, relevant to smart city initiatives. Searches were conducted using the keywords "transport or mobility" and "smart city", and “"smart transport' or 'smart mobility" and "city". We considered papers that refer to ICT solutions and only the most influential ones, i.e., papers with more than two years since their publication with no citations were discarded. In total, 18 papers were selected.

\subsubsection{State of practice}

To identify smart cities, we conducted searches using Google search engine and the keywords “'smart city' or 'intelligent city' or 'living labs' or 'ciudad inteligente", in conjunction with three continent names, America, Asia, and Europe, to cover countries with different levels of development. For each city, the following selection criteria was applied: availability of information of mobility services in government websites, and diversity of mobility services with respect to those already collected. In total 9 cities were selected as shown in Table 1.

All the nine cities have been recognized as cities standing out in

\footnotetext{
${ }^{2}$ https://www.scopus.com/.
} 
Table 1

Smart cities selected.

\begin{tabular}{|c|c|c|c|}
\hline Continent & City & Country & Reference $^{\mathrm{a}}$ \\
\hline \multirow[t]{3}{*}{ America } & Curitiba & Brazil & http://www.curitiba.pr.gov.br \\
\hline & Seattle & USA & https://www.seattle.gov \\
\hline & Surrey & Canada & $\begin{array}{l}\text { https://surrey.ca/city-government/ } \\
\text { 15430.aspx }\end{array}$ \\
\hline \multirow[t]{2}{*}{ Asia } & Dubai & $\mathrm{UAE}$ & $\begin{array}{l}\text { http://www.dubai.ae/en/Pages/ } \\
\text { default.aspx }\end{array}$ \\
\hline & Songdo & South Korea & http://songdoibd.com/about/ \\
\hline \multirow[t]{4}{*}{ Europe } & Amsterdam & The Netherlands & https://amsterdamsmartcity.com \\
\hline & Barcelona & Spain & http://smartcity.bcn.cat/es/ \\
\hline & Copenhagen & Denmark & https://stateofgreen.com/en \\
\hline & Vienna & Austria & https://smartcity.wien.gv.at/site/en/ \\
\hline
\end{tabular}

a The URL references provided were accessed between October 2014 and Nov 2014.

some of the six dimensions of a smart city: Curitiba is recognized ${ }^{3}$ by its integrated transportation system and land use planning ${ }^{4}$; Seattle is a leading example in sustainability in terms of energy efficiency and transportation, ${ }^{5}$ and has recently joined a national network of smart cities $^{6}$; Surrey was recognized as one of the top seven intelligent communities of $2016^{7}$; Dubai was recognized as the leading smart city initiative in the Gulf ${ }^{8}$; Songdo is well known because the city was conceived and built from scratch ${ }^{9}$; Amsterdam was recognized with the Smart City World Award in 2012 and is an example in living labs, and mobility and smart grid programs ${ }^{10}$; Barcelona was recognized as World's Smartest City in 2015 because of its programs in smart traffic management and smart grids ${ }^{11}$; Copenhagen is recognized due to the Copenhagen Connecting initiative, awarded as best project with the Smart City World Award in $2014^{12}$; and Vienna was recognized with the Smart City World Award in $2016^{13}$ for its integrated energy research.

The data was analysed based on three constructs - What, Who and Why. Each of the constructs addresses one of the formulated research questions, or meta-characteristics, as follows:

a) WHAT - RQ1: What is the service about? The construct explores the aim and type of the service delivered.

b) HOW - RQ2: How is the service delivered? The construct investigates the technology and the channels used to implement and deliver the service.

c) WHY - RQ3: Why is the service relevant? The construct assesses for whom the service is delivered and the public value delivered through the service.

\subsection{Taxonomy construction}

This step is an iterative process. In each iteration, a strategy is selected to build or refine the taxonomy, a series of steps are conducted depending on the selected strategy, and the ending conditions are

\footnotetext{
${ }^{3}$ https: //sustainabledevelopment.un.org/index.php?page $=$ view\&type $=99 \& \mathrm{nr}=57 \&$ menu $=1449$ last visited on Dec 2016 .

${ }^{4}$ http://www.ippuc.org.br last visited on Dec 2016.

5 http://smartcitiescouncil.com/article/why-seattle-sustainability-superstar last visited on Dec 2016

${ }^{6}$ https://www.seattle.gov/tech/initiatives/smart-cities last visited on Dec 2016.

7 https://surrey.ca/city-government/15430.aspx last visited on Dec 2016.

8 http://e.huawei.com/ae/news/ae/2015/2016/201610181814 last visited on Dec 2016.

${ }^{9}$ http://songdoibd.com/about/ last visited on Dec 2016.

10 http://www.smartcityexpo.com/past-editions-2012 last visited on Dec 2016.

11 https://eu-smartcities.eu/content/barcelona-world's-smartest-city-2015 last visited on Dec 2016.

12 http://www.smartcityexpo.com/past-editions-2014 last visited on Dec 2016.

13 http://www.smartcityexpo.com/en/past-editions-2016 last visited on Dec 2016.
}

checked to decide whether another iteration is needed.

First, the top-level dimensions of the taxonomy were conceptualized following a conceptual to empirical approach, i.e., for each research question (RQ), we identified concepts that capture the essence of the question. In particular, six dimensions were identified at this stage: type of services as logical consequences of RQ1; applied technologies and delivery channels, as logical consequences of RQ2; and benefits, beneficiaries and users, as logical consequences of RQ3. Second, various iterations were conducted following an empirical to conceptual approach until the ending conditions were met. In each iteration, services of the initiatives were grouped based on common characteristics under the different dimensions, given rise to the various sub-categories of each dimension. For example, in the type of user dimension, we identified groups of services for people who drive cars and for cyclists. Intuitively, these groups gave rise to the sub-category drivers. This was conducted with the help of conceptual maps to group services and for this we used the XMind mind-mapping tool. During this process, it was evident that many services provided similar functionality with small variations, resulting in the identification of the common functionality dimension, which can be seen as a logical consequence of RQ2.

\subsection{Validation}

This step comprises the validation of the taxonomy and the integration of the received feedback.

We organized two focus groups meetings with international government practitioners and academic experts with experience on the smart mobility domain. The two meetings conducted in Guimarães, Portugal, one at Comunidade Intermunimunicipal do Ave ${ }^{14}$ and one at United Nations University-EGOV ${ }^{15}$ (UNU-EGOV), were organized as two-hour session, including 20-minutes presentation of the taxonomy, followed by a discussion among participants. The aim was to discuss the suitability of the taxonomy, validity of the concepts, completeness, weaknesses, and improvements. In total, the meetings were attended by 5 government experts from China (working for Beijing Government), Uganda (working for Ministry of ICT, Uganda), Portugal (working for Comunidade Intermunicipal do Ave), and Denmark (former government official of the Danish Agency for Digitization), and four academics from UNU-EGOV. Both meetings provided valuable feedback for validating the content of the taxonomy as well as for its improvement. In particular, a new dimension was incorporated, level of maturity, which can be seen as a logical consequence of RQ2. This resulted in a new iteration of step 3 , where the characteristics for this dimension were identified following a conceptual to empirical approach based on existing theory.

In addition, the content of the taxonomy has been validated based on traceability, i.e., the content has been produced only based on collected data and references are provided for each concept.

\subsection{Maintenance}

This step comprises the identification of the stakeholders responsible for the continued maintenance and evolution of the taxonomy, and the definition of guidelines for the stakeholders. These topics are discussed in Section 7.

\section{State of the art on smart mobility services}

The following sections outline the state of research and practice on smart mobility services.

\footnotetext{
14 http://www.cim-ave.pt.

15 https://egov.unu.edu.
} 


\subsection{State of research}

Below we describe each paper describing an ICT solution. A further classification of these papers is provided in Section 5.1 when discussing the type of services identified.

Findings from the state of research assessment include: P1) a software platform to automate the collection and aggregation of large scale context information provided by different sources, which serves to build an intelligent transportation system to better understand traffic problems (Dobre \& Xhafa, 2014); P2) an ICT platform for an intelligent transportation system that updates users with real time information regarding flexible transport, like bicycles and car sharing, and traditional transport systems, such as optimal routes, delays in public transport, available parking places, and the state of the roads with data collected from various sources (Anastasi et al., 2013); P3) an intelligent urban traffic management system that detects congestions from various information sources, such as sensors at road intersections and on public transport vehicles (Schnitzler et al., 2014); P4) a fuzzy neuronal network to optimize traffic light patterns and provide priority to public buses and emergency vehicles (Horng, Li, \& Cheng, 2013); P5) an adaptive system for intelligent traffic management (Paweł Gora \& Wasilewski, 2014); P6) a framework for designing business services, and its application to mobility services (Motta, You, Sacco, \& Miceli, 2014); P7) a cloud-based car parking middleware for smart cities based on Internet of Things, including sensors to detect available parking places, wireless technologies to transmit the information sensed, and functionality to provide cloud-based parking services (Ji, Ganchev, O'Droma, Zhao, \& Zhang, 2014); P8) a large scale traffic simulation platform for transport authorities to optimize city transportation (Suzumura et al., 2012); P9) a multi-agent simulation system that incorporates real world data into the simulation, e.g. snowstorms, to improve smart transportation planning (Bakillah, Liang, \& Zipf, 2012); P10) a real time mobility assistant providing information about multimodal journeys (Motta, Sacco, Belloni, \& You, 2013). P11) an augmented reality application to access public transport information, such as buses arrival times and routes (Pokriü, Krpo, \& Pokriü, 2015); P12) a generic framework for mobile participatory sensing with a live transit feed service providing real time information about public transport services (Szabo et al., 2013); P13) an application layer solution for a geo-casting function for smart on-board units in vehicles. The aim is to automatically detect car accidents and disseminate information about the incidents to near vehicles and authorities, like hospitals and police stations. (Tarapiah, Atalla, Autonomo, \& Alsayid, 2014); P14) an assistance system for bus drivers to adjusts the driving speed to arrive at intersections when traffic lights are still green, assuming buses have their own lane as in the case of Rapid Transit Buses (Seredynski, Ruiz, Szczypiorski, \& Khadraoui, 2014); P15) an electrically powered one person transport system for pedestrian areas, such as historical city centres, enabling accessibility for people with mobility disabilities (Cepolina \& Farina, 2012); P16) an adaptive traffic management system with a fuzzy logic scheme to reduce traveling times of emergency vehicles (Djahel, Smith, Wang, \& Murphy, 2015); P17) a platform for dynamic carpooling in the city, i.e., to share car rides that are published in real time, contrary to typical carpooling services that required planning in advanced (Mallus, Colistra, Atzori, Murroni, \& Pilloni, 2017); and P18) an approach to reduce traveling times suggesting customized routes to vehicles to avoid traffic jams using vehicle-to-infrastructure communication (Stolfi \& Alba, 2014).

\subsection{State of practice}

Below we describe the smart mobility initiatives identified for each city. The initiatives are further classified under each construct of the taxonomy in Section 5. References to each initiative are provided in Table 11 in the Appendix.

\subsubsection{Amsterdam}

S01) Moby Park, a mobile application and website facilitating finding, booking and paying parking places and getting driving guidance to arrive to a selected parking place. S02) A platform for lorry drivers for finding and booking parking places, and for receiving driving guidance. S03) A mobile application providing real time driving guidance, using calendar data to suggest when to start driving so to arrive on time to scheduled appointments. S04) A mobile application providing real time driving guidance to emergency vehicles. S05) WeGo, a peer-to-peer car-sharing platform for car owners to share their cars, and for non-car owners to find, book and pay for available cars. It also enables to lock and unlock cars.

\subsubsection{Vienna}

S06) An energy saving tram that monitors different aspects of the journeys and takes proactive measures to increase passengers' comfort, e.g., it controls the amount of incoming fresh air and sunlight. S07) Smile, a mobile app to plan multi-modal journeys, to book and pay mobility services, to open doors at parking places and shared vehicles, and to access mobility records.

\subsubsection{Copenhagen}

S08) Copenhagen Connecting, an integrated system tracking moving assets for security or location purposes, sharing real time data about parking places, and monitoring and controlling traffic flow on real time. It also enables traffic light optimization, and dynamic pricing of parking and road tolls based on current parking demand and traffic flow. S09) A cloud-based dashboard to study the efficiency of traffic light patterns, traffic behaviour, and correlations between traffic and other influencing factors. S10) An integrated system to coordinate traffic lights and provide faster green lights for buses, to detect parking places, to inform passengers about delays and alternative routes, and to widen or shrink lanes on rush hours through dynamic led signs. S11) Rejseplanen, a real time multi-modal journey planner with customizable searches, and displays with information about transport. S12) An SMS service to buy public transport tickets.

\subsubsection{Barcelona}

S13) A remote device for blind people to command traffic lights to emit an audible sound to safely cross the street. S14) An intelligent traffic light system to control traffic lights and provide faster green lights for emergency vehicles. S15) ApparkB, a mobile app to pay street parking places, providing access to a monthly summary of expenses. S16) App\&Town, a real time multi-modal journey planner for public transport gathering information from various sources. S17) An SMS service to access transport-related information, including availability of public bicycles, and cars seized by authorities. S18) JoinUp Taxi, a mobile app to share a taxi, rate taxi drivers and users, estimating money and $\mathrm{CO}_{2}$ emissions saved by sharing a taxi. S19) WeSmartPark, a mobile app and website to find available parking places, get driving guidance, book places and issue payments when leaving the parking place, automatically opening parking doors.

\subsubsection{Curitiba}

S20) Services for public buses including wireless Internet on-board, and smart pass payment, providing real time information about the service; and monitoring of vehicles and their performance, e.g., measuring passenger demand to send more vehicles to cover a route, and comparing estimated traveling times with actual times. S21) A service providing an online integrated itinerary comprising information about various types of buses. S22) A service estimating traveling times by detecting and monitoring cars entering and leaving specific locations. S23) A system to control traffic lights based on current traffic conditions or by request. S24) A system providing faster green lights for public buses, and monitoring of buses to identify critical and optimal road intersections to improve traveling times. S25) A system providing real 
time traffic information through dynamic message signs. S26) An Operational Control Centre to monitor traffic and incidents in real time through CCTV. S27) Radars and cameras to detect vehicles that exceed the speed limit, fail to stop on a red light, or stop on the pedestrian walk.

\subsubsection{Songdo}

S28) A system for optimizing traffic light aiming at resolving traffic congestions, which are detected by analysing geo-location information provided by RFID tags on cars.

\subsubsection{Seattle}

S29) A website providing real time information of available parking places, and a system of dynamic message signs providing guidance to the nearest available parking place. S30) Online payment of parking and traffic fines. S31) An online interactive map with information about planned events that affect mobility. S32) A system to monitor traffic flows and to automatically detect license plates for security and law enforcement, estimating traveling times. S33) A system to adjust traffic lights based on historical and current data, and to provide faster green lights for public buses. S34) A system providing real time information about traffic through dynamic message signs. S35) An online interactive map publishing real time traffic information, including incidents, planned events, and access to CCTV cameras feeds.

\subsubsection{Dubai}

S36) Nol Card, a smart card to seamlessly pay for different mobility services, including public transport and parking places. S37) Smart Taxi, a mobile app to request taxis, choose the type of vehicle, find out the location of taxis, get information about the driver, and rate the driver's driving skills. S38) A multi-modal journey planner with customizable searches and estimations of traveling times and costs. S39) A mobile app to find nearby available parking places and to receive driving guidance to reach the parking place.

\subsubsection{Surrey}

S40) A mobile application for car-pooling. S41) A website for carsharing, including a booking service. S42) A system to control traffic lights and to adjust them for faster emergency responses, as well as to guide emergency vehicles, and to analyse traffic behaviour.

\section{A taxonomy of smart mobility services}

The main dimensions defined for the taxonomy of smart mobility services are depicted in Fig. 2. The identified values for each dimension are defined and illustrated in the following sections.

\subsection{Type of service}

We identify 12 types of services. Table 2 describes each type and exemplifies it by classifying each initiative described in Section 4.

\subsection{Level of maturity}

We define level of maturity following the United Nations four-stage digital public service maturity model (Layne \& Lee, 2001) to classify standard digital public services, and the digital public service innovation framework proposed in (Bertot, Estevez, \& Janowski, 2016) to classify innovative digital public services. Table 3 describes each level of maturity and classifies each initiative. We identify services for all categories.

\subsection{Types of users}

In this context, a user refers to any actor receiving a smart mobility service. We identify five main types of users. Table 4 describes each category and classifies each initiative.

\subsection{Technology}

This concept focuses on ICT tools and computational techniques applied for delivering smart mobility services. We identify nine main types of ICT tools, and two computational techniques. Table 5 describes each technology and classifies the initiatives that rely on them.

\subsection{Delivery channel}

We define channel as the mean used by an administration to interact with and to deliver smart mobility services to its stakeholders. We identify five types of delivery channels. Table 6 describes each channel and classifies the services that rely on them for their delivery.

\subsection{Benefits and beneficiaries}

We define benefit as a positive outcome obtained from delivering smart mobility services. We identify direct and indirect benefits delivered to different stakeholders and we classify them according to the smart city dimensions. In addition, we relate each benefit with public values identified in the literature (Jørgensen \& Bozeman, 2007). Table 7 describes the benefits and classifies the services that deliver them.

Smart mobility was defined in Section 1 . The rest of the smart city dimensions are defined as follows. Smart economy refers to city competitiveness, including innovation, entrepreneurship, and productivity. Smart environment concerns issues related to natural resources and attractive natural conditions of the city, like green spaces, and climate. Smart governance considers citizens' participation in decision-making processes; public and social services for various stakeholders; as well as administrative processes. Smart living focuses on issues related to quality of life, including culture, health, housing, education, and tourism. Finally, smart people addresses human and social capital, including level of education and quality of social interactions.

Associated with benefits, we can identify beneficiaries. A

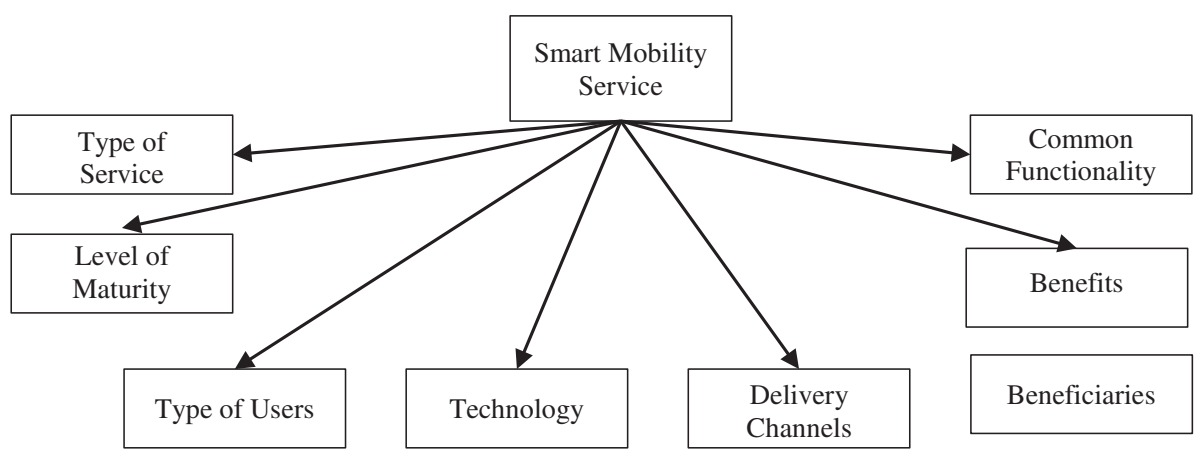

Fig. 2. A smart mobility service taxonomy. 
Table 2

Type of service.

\begin{tabular}{|c|c|c|}
\hline Category & Description & Examples \\
\hline Driving guidance & $\begin{array}{l}\text { It provides guidance to drivers about the best route for moving from one place to another, including } \\
\text { fixed or real time information of issues affecting mobility. Routes can be selected based on different } \\
\text { criteria, such as the shortest or fastest route }\end{array}$ & $\begin{array}{l}\text { S01, S02, S03, S04, S19, S39, S42 } \\
\text { P18 }\end{array}$ \\
\hline Improving transport resources & $\begin{array}{l}\text { It refers to enhanced functionality included in transport resources, usually related to a specific goal, } \\
\text { such as energy savings, enhancing the travel experience, and reducing } \mathrm{CO}_{2} \text { emissions }\end{array}$ & $\begin{array}{l}\text { S06, S20 } \\
\text { P13, P14, P15 }\end{array}$ \\
\hline $\begin{array}{l}\text { Improving transport } \\
\text { infrastructure }\end{array}$ & $\begin{array}{l}\text { It refers to enhanced functionality delivered to transport infrastructure such as parking places, roads, } \\
\text { traffic lights, etc., including devices to detect empty parking places, or dynamic message signs to inform } \\
\text { about traffic }\end{array}$ & S07, S10, S13, S19, S25, S29, S34 \\
\hline Journey planners & $\begin{array}{l}\text { It provides instructions for moving from one place to another using one or multiple types of transport } \\
\text { for a single journey. Instructions include types of transport available, travel and arrival times, and } \\
\text { guidance for commuting between them. Guidance can be personalized with different criteria such as the } \\
\text { cheapest, fastest or most environmentally friendly journey, and support for transporting wheelchairs or } \\
\text { bicycles, among others }\end{array}$ & $\begin{array}{l}\text { S07, S11, S16, S20, S21, S38, P2, } \\
\text { P6, P10 }\end{array}$ \\
\hline Locating objects & It enables to locate, usually in real time, vehicles in the city such as cars, public bicycles or public buses & S08, S17, S37 \\
\hline Monitoring traffic & $\begin{array}{l}\text { It enables authorities to monitor, analyse, and get insights about traffic and pedestrians, such as } \\
\text { detecting congestions, estimating traveling times, and detecting cars' illegal behaviour. It can rely on } \\
\text { monitoring of simulated data, e.g., to evaluate the impact of events on traffic, such as, weather, road } \\
\text { closure, and adjustments in traffic lights patterns. Recorded data can serve as evidence of incidents for } \\
\text { authorities }\end{array}$ & $\begin{array}{l}\text { S08, S22, S26, S27, S32, S42, P1, } \\
\text { P2, P3, P5, P8, P9 }\end{array}$ \\
\hline Monitoring transport & $\begin{array}{l}\text { It enables transport authorities to monitor public transport vehicles to get insights about onboard } \\
\text { events, vehicles' performance based on current and expected traveling times, number of passengers, and } \\
\text { incidents, among others }\end{array}$ & S20, S24 \\
\hline Parking & $\begin{array}{l}\text { It enables users to search, book, and pay for parking places. It can also include functionality for } \\
\text { managing the parking facilities, offering parking places and managing interactions between the parking } \\
\text { provider and the users }\end{array}$ & $\begin{array}{l}\text { S01, S02, S08, S10, S15, S19, S29, } \\
\text { S39, P2, P7 }\end{array}$ \\
\hline Payment & $\begin{array}{l}\text { It enables to seamlessly pay transport-related services, such as tickets for single or multi-modal } \\
\text { journeys, parking places, energy for electric vehicles, road tolls, and use of public bicycles, among } \\
\text { others }\end{array}$ & $\begin{array}{l}\text { S01, S05, S07, S12, S15, S19, S20, } \\
\text { S30, S36 }\end{array}$ \\
\hline Reporting mobility & $\begin{array}{l}\text { It provides various stakeholders with information about events affecting mobility such as planned } \\
\text { events, incidents, alternative routes, and current traveling times, among others }\end{array}$ & $\begin{array}{l}\text { S10, S25, S31, S34, S35, P2, } \\
\text { P11-P13 }\end{array}$ \\
\hline Sharing transport & $\begin{array}{l}\text { It enables to share vehicles (car-sharing) and journeys (car-pooling), including, announcing, searching, } \\
\text { booking, and paying for cars and shared journeys, and accessing to vehicles }\end{array}$ & S05, S18, S40, S41, P17 \\
\hline Traffic light optimization & $\begin{array}{l}\text { It allows adjusting traffic light patterns based on different factors including current traffic flow, } \\
\text { historical and simulated data, and approaching of special types of vehicles such as emergency vehicles } \\
\text { and public buses. The main aim of this type of service is to respond to the changing demands in traffic } \\
\text { flow and to prioritize the moving of special vehicles }\end{array}$ & $\begin{array}{l}\text { S08, S09, S10, S14, S23, S24, S28, } \\
\text { S33, S42, P4, P16 }\end{array}$ \\
\hline
\end{tabular}

Table 3

Level of maturity.

\begin{tabular}{|c|c|c|}
\hline Category & Description & Examples \\
\hline \multicolumn{3}{|c|}{ Standard services } \\
\hline Emerging & $\begin{array}{l}\text { Informational services providing basic online information with only one-way interaction between users } \\
\text { and the service provider }\end{array}$ & S25, S29 \\
\hline Enhanced & $\begin{array}{l}\text { Services with enhanced one-way communication or basic two-way interactions between users and the } \\
\text { service provider }\end{array}$ & S31 \\
\hline Transactional & $\begin{array}{l}\text { Services enabling complete transactions online with two-way communication between users and the } \\
\text { service provider }\end{array}$ & S13, S17, S30 \\
\hline Connected & Integrated seamless services, delivered using multiple technologies and platforms, and highly interactive & $\begin{array}{l}\text { S01-S05, S07-S12, S14-S16, S18-S21, S24-S27, } \\
\text { S29, S32-S42 }\end{array}$ \\
\hline \multicolumn{3}{|c|}{ Innovative services } \\
\hline Transparent & Services publishing information about service context and decisions made by the service provider & S07, S31, S35, S37 \\
\hline Participatory & Services using participatory techniques such as crowdsourcing & S16, S18 \\
\hline Anticipatory & Services that anticipate to the needs of the user & S03 \\
\hline Co-created & $\begin{array}{l}\text { Services delivered collaboratively between government, private sector, and/or non-government } \\
\text { organizations, and/or citizens }\end{array}$ & S01, S05, S18, S40, S41 \\
\hline Personalized & Customizable service delivery based on user's preferences and specific needs & S07, S11, S16, S18, S38 \\
\hline Context-aware & Services or information provided based on the user's context information & S01, S02, s04, S07, S10, S20, S39 \\
\hline Context-smart & $\begin{array}{l}\text { Services that apply intelligence and leverage on the knowledge of context-related information to take } \\
\text { action at the needed moment }\end{array}$ & S02-S03, S06, S08-S10, S14, S19, S22-S24, S28, S33 \\
\hline
\end{tabular}

beneficiary refers to the actor who receives a benefit from a smart mobility service. From the types of users identified in Section 5.3, we identify transport authority, driver, passenger, and resource owner, as beneficiaries. We also identify the society, as beneficiary, representing all kind of social actors. Table 8 illustrates this relationship. In addition, due to the faceted structure, we can easily relate information in multiple ways. Thus, we can relate types of services with benefits delivered; as Fig. 3 shows the type of service contributing to delivering each benefit.

\subsection{Common functionality}

By common functionality we refer to a given feature that is present in more than one service, producing different results depending only on different values of certain parameters. Fig. 4 illustrates this concept, showing the functionality identified for two services, S01) parking sharing (top left) and S05) car sharing (bottom left). In both cases, users request a resource, a parking place or a car, which is near a given location. The object of the request could be potentially any kind of 
Table 4

Types of users.

\begin{tabular}{|c|c|c|}
\hline Category & Description & Examples \\
\hline Transport authority & $\begin{array}{l}\text { A government agency responsible for the licensing of public and commercial vehicles, for designing, } \\
\text { building and maintaining land transport resources and infrastructures, and for regulating and } \\
\text { monitoring land transport in a given territory }\end{array}$ & S08-S10, S14, S20, S22-S28, S32, S33, S42 \\
\hline Driver & $\begin{array}{l}\text { A person who is licensed for driving a vehicle or is able to drive a vehicle that does not require a } \\
\text { permit. Drivers are further classified into Motor-Vehicle Driver, and Bicycle Driver }\end{array}$ & $\begin{array}{l}\text { S01, S02-S04, S05, S07, S08, S10, S15, S17, S19, } \\
\text { S25, S29-S31, S34-S36, S39-S41, S42 }\end{array}$ \\
\hline Passenger & $\begin{array}{l}\text { A person who travels in a vehicle without participating in its operation. Passengers are further } \\
\text { classified into public and non-public transport, and taxi passenger }\end{array}$ & $\begin{array}{l}\text { S06, S07, S10, S11, S12, S16, S18, S20, S21, } \\
\text { S36-S38, S40 }\end{array}$ \\
\hline Resource owner & $\begin{array}{l}\text { A person who possesses a transport-related resource, such as a vehicle, parking place, garage, and is } \\
\text { willing to share it or rent it }\end{array}$ & S01, S05 \\
\hline Pedestrian & A person who walks through the city & $\mathrm{S} 13, \mathrm{~S} 16, \mathrm{~S} 23$ \\
\hline
\end{tabular}

Table 5

Technology.

\begin{tabular}{|c|c|c|}
\hline Category & Description & Examples \\
\hline \multicolumn{3}{|l|}{ ICT tools } \\
\hline Internet access & $\begin{array}{l}\text { It refers to technologies enabling a computer terminal, mobile device and computer network to } \\
\text { connect to Internet for accessing online services. Internet access is provided by various wired or } \\
\text { wireless technologies offering a wide range of data transfer speed }\end{array}$ & $\begin{array}{l}\text { S01, S02, S05, S07, S11, S19-S21, } \\
\text { S29-S31, S35, S40, S41 }\end{array}$ \\
\hline Mobile broadband & $\begin{array}{l}\text { It refers to the various generations ( } 2 \mathrm{G}, 3 \mathrm{G}, 4 \mathrm{G} \text {, and so on) of mobile telecommunications } \\
\text { technology for mobile devices and services and networks that fulfil a set of standards defined by the } \\
\text { International Telecommunication Union (ITU). It contributes to access services on the move }\end{array}$ & $\begin{array}{l}\text { S01-S05, S07, S11, S15, S16, S18, } \\
\text { S19, S21, S29, S35, S37-S41 }\end{array}$ \\
\hline Wi-Fi access points & $\begin{array}{l}\text { It refers to a device that enables wireless devices to connect to a wired network, and to detect and } \\
\text { geo-locate Wi-Fi pings made from mobile Wi-Fi enabled devices }\end{array}$ & S08, S20 \\
\hline Near field communication (NFC) & $\begin{array}{l}\text { It refers to a wireless connectivity standard to exchange data using magnetic field induction } \\
\text { between two devices located at few centimetres from each other }\end{array}$ & S36 \\
\hline Closed circuit television (CCTV) & $\begin{array}{l}\text { It refers to a TV system, which signals are not publicly distributed but are used to monitor a given } \\
\text { area, primarily for surveillance and security purposes }\end{array}$ & S20, S22, S26, S27, S32, S35, S42 \\
\hline Global positioning system (GPS) & $\begin{array}{l}\text { It refers to a satellite navigation system enabling to locate an object in longitude, latitude and } \\
\text { altitude with high precision }\end{array}$ & $\begin{array}{l}\text { S01-S04, S05, S07, S10, S11, S16, } \\
\text { S18-S20, S39-S41 }\end{array}$ \\
\hline $\begin{array}{l}\text { Radio frequency identification } \\
\quad \text { (RFID) }\end{array}$ & $\begin{array}{l}\text { It refers to a technology that enables data transfer through wireless use of electromagnetic fields. } \\
\text { RFID technology relies on identifying and tracking tags attached to objects }\end{array}$ & S08, S10, S19, S24, S28, S33 \\
\hline Smart sensors & $\begin{array}{l}\text { It refers to a device able to sense and convert real-world data into a digital data stream and } \\
\text { transmit it wirelessly }\end{array}$ & S06, S24, s27, S33, S39 \\
\hline Inductive-loop traffic detector & $\begin{array}{l}\text { A kind of smart sensor in the pavement. It is an electrical conducting loop to detect vehicles } \\
\text { arriving or passing through }\end{array}$ & S22 \\
\hline \multicolumn{3}{|l|}{ Computational techniques } \\
\hline Simulation algorithms & $\begin{array}{l}\text { It refers to computational algorithms able to produce models that imitate a current or probable } \\
\text { system and its progression }\end{array}$ & S09, S33 \\
\hline Video recognition & $\begin{array}{l}\text { It refers to computational techniques enabling to detect, locate and recognize objects and events in } \\
\text { a video feed }\end{array}$ & S22, S32 \\
\hline
\end{tabular}

transport-related resource, such as a bus stop, train station or a bicycle. However, the process for handling the request is the same: searching an object in a database that satisfies a given relation, e.g., "is closed to" with a given parameter, e.g., a location. This is an example of common functionality used by more than one service. We call such function "request nearby resources" and the parameters include type of resource and location. The common functionality and expected parameters identified for both services is shown in Fig. 4 (right).

A summary of the common functionality identified in smart mobility services together with the services that use such functions is presented in Table 9.

\section{Validation}

The taxonomy presented was constructed based on a detailed analysis of the state of research and practice of smart mobility services, following the methodology and validation approach described in Section 3. Below we discuss further decisions underpinning the

Table 6

Delivery channel

\begin{tabular}{|c|c|c|}
\hline Category & Description & Examples \\
\hline Dynamic message sign & $\begin{array}{l}\text { It refers to an electronic message board used to provide up-to-the minute information to drivers } \\
\text { and the public }\end{array}$ & S25, S29, S34 \\
\hline Mobile device and applications & $\begin{array}{l}\text { It refers to a handheld computing device with capacity for running application software, e.g., } \\
\text { smart mobile phone or tablet }\end{array}$ & $\begin{array}{l}\text { S01-S05, S07, S10, S11, S15, S16, S18, S19, } \\
\text { S37-S40 }\end{array}$ \\
\hline Smart card & $\begin{array}{l}\text { It refers to a plastic card embedded with a microchip and/or NFC facilitating data storage and } \\
\text { exchange }\end{array}$ & S36 \\
\hline Short message service (SMS) & $\begin{array}{l}\text { It refers to a text message sent through a mobile device, with a maximum of } 160 \text { characters for } \\
\text { Latin alphabets, or } 70 \text { for Chinese or Arabic alphabets }\end{array}$ & S12, S17 \\
\hline Website & It refers to a connected set of Internet pages facilitating access to online resources & $\begin{array}{l}\text { S01, S02, S05, S11, S19, S21, S29-S31, S35, } \\
\text { S38, S40, S41 }\end{array}$ \\
\hline
\end{tabular}




\begin{tabular}{|c|c|c|c|}
\hline Category & Description & Public values & Examples \\
\hline \multicolumn{4}{|l|}{ Smart economy } \\
\hline $\begin{array}{l}\text { Generating new sources of } \\
\text { incomes }\end{array}$ & $\begin{array}{l}\text { It refers to enabling new sources of earnings, e.g., from sharing } \\
\text { owned resources }\end{array}$ & Citizen's self-development & S01, S05 \\
\hline Generating personal savings & It refers to reducing personal expenditures dedicated to mobility & Productivity; effectiveness & $\begin{array}{l}\text { S01, S02, S03, S15, S18, S19, } \\
\text { S29, S30, S36, S39, S40 }\end{array}$ \\
\hline Facilitating a sharing economy & $\begin{array}{l}\text { It refers to the use of ICT to support the sale or rent of goods and } \\
\text { services via online markets. It can be peer-to-peer, business to } \\
\text { consumer, etc. }\end{array}$ & Cooperativeness & S01, S05, S18, S40, S41 \\
\hline \multicolumn{4}{|l|}{ Smart governance } \\
\hline Resolving conflicts & $\begin{array}{l}\text { It refers to providing evidences to authorities to react faster to } \\
\text { resolve conflicts generated by traffic or people }\end{array}$ & $\begin{array}{l}\text { Effectiveness; Common good; } \\
\text { Productivity; Rule of law; Protection of } \\
\text { rights of the individual }\end{array}$ & S20, S26, S27, S32, S42 \\
\hline Detecting illegal behaviour & $\begin{array}{l}\text { It refers to facilitating the detection of illegal behaviour } \\
\text { committed by drivers }\end{array}$ & $\begin{array}{l}\text { Rule of law; Effectiveness; Common } \\
\text { good }\end{array}$ & S27 \\
\hline \multicolumn{4}{|l|}{ Smart mobility } \\
\hline Facilitating journeys & $\begin{array}{l}\text { It refers to enabling journey planning providing alternatives } \\
\text { scenarios for moving in the city using different types of } \\
\text { transport }\end{array}$ & $\begin{array}{l}\text { Common good; Public interest; } \\
\text { Productivity; Effectiveness }\end{array}$ & S07, S10, S11, S16, S20, S21, S38 \\
\hline Reducing commuting time & $\begin{array}{l}\text { It refers to providing alternatives routes and guidance for } \\
\text { reducing the amount of time required to move from one place to } \\
\text { another, considering one or more types of transport }\end{array}$ & $\begin{array}{l}\text { Common good; Public interest; } \\
\text { Productivity; Effectiveness; Timeliness }\end{array}$ & $\begin{array}{l}\text { S01, S02, S03, S04, S08, S09, } \\
\text { S10, S14, S19, S23, S24, S28, } \\
\text { S29, S31, S33-S35, S39, S42 }\end{array}$ \\
\hline $\begin{array}{l}\text { Contributing to reducing traffic } \\
\text { congestions }\end{array}$ & It refers to improving traffic flow & $\begin{array}{l}\text { Common good; Public interest; } \\
\text { Effectiveness; Sustainability }\end{array}$ & $\begin{array}{l}\text { S02, S03, S08, S09, S10, S23, } \\
\text { S28, S33, S42 }\end{array}$ \\
\hline Facilitating seamless payment & $\begin{array}{l}\text { It refers to facilitating seamless and on-the-move payment of } \\
\text { smart mobility services }\end{array}$ & Productivity; Effectiveness & S01, S07, S12, S19, S20, S30, S36 \\
\hline \multicolumn{4}{|l|}{ Smart environment } \\
\hline Reducing $\mathrm{CO}_{2}$ emissions & It refers to contributing to reducing $\mathrm{CO}_{2}$ emissions. & $\begin{array}{l}\text { Sustainability; Common good; Public } \\
\text { interest; Ethical consciousness }\end{array}$ & $\begin{array}{l}\text { S01, S02, S03, S08, S09, S10, } \\
\text { S18, S19, S23, S28, S29, S33, } \\
\text { S39, S40, S42 }\end{array}$ \\
\hline $\begin{array}{l}\text { Contributing to becoming a } \\
\text { paperless society }\end{array}$ & $\begin{array}{l}\text { It refers to digitizing service delivery, avoiding the use of paper- } \\
\text { based forms and interactions }\end{array}$ & $\begin{array}{l}\text { Sustainability; Common good; Public } \\
\text { interest; Ethical consciousness }\end{array}$ & $\begin{array}{l}\text { S01, S07, S12, S15, S19, S20, } \\
\text { S30, S36 }\end{array}$ \\
\hline $\begin{array}{l}\text { Using environmentally-friendly } \\
\text { transport media }\end{array}$ & $\begin{array}{l}\text { It refers to encouraging the use of means of transport which are } \\
\text { classified as environmentally-friendly, like car-pooling, public } \\
\text { transport, low emission vehicles, vehicles using } \\
\text { environmentally-friendly fuels, etc. }\end{array}$ & $\begin{array}{l}\text { Sustainability; Common good; Public } \\
\text { interest; Ethical consciousness }\end{array}$ & $\begin{array}{l}\text { S06, S07, S10, S11, S14, S16, } \\
\text { S20, S21, S24, S33, S38 }\end{array}$ \\
\hline \multicolumn{4}{|c|}{ 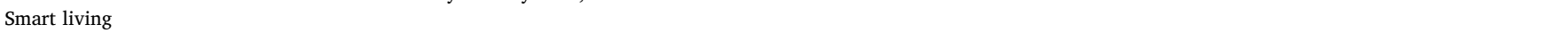 } \\
\hline Improving safety & It refers to improving safety conditions for city dwellers & $\begin{array}{l}\text { Rule of law; Protection of rights of the } \\
\text { individual }\end{array}$ & S18, S20, S25, S32, S34, S35, S37 \\
\hline Improving quality of life & $\begin{array}{l}\text { It refers to improving the quality of life of city dwellers in terms } \\
\text { of saving time for moving in the city, increasing comfort, } \\
\text { simplifying tasks and use of services, etc. }\end{array}$ & $\begin{array}{l}\text { Protection of rights of the individual; } \\
\text { Human dignity; Common good }\end{array}$ & $\begin{array}{l}\text { S02-S04, S06, S07, S08, } \\
\text { S11-S17, S19-S21, S24, S29, } \\
\text { S30, S33, S36, S38, S39 }\end{array}$ \\
\hline Reducing isolation & $\begin{array}{l}\text { It refers to providing access to alternative and more economic } \\
\text { transport services in places where public transport is not } \\
\text { available, such as access to share rides to move to hospitals, } \\
\text { work, etc. }\end{array}$ & $\begin{array}{l}\text { Protection of minorities; Protection of } \\
\text { rights of the individual }\end{array}$ & $\mathrm{S} 05, \mathrm{~S} 18, \mathrm{~S} 40, \mathrm{~S} 41$ \\
\hline Developing social values & $\begin{array}{l}\text { It refers to the development of social values, like sharing and } \\
\text { trust }\end{array}$ & $\begin{array}{l}\text { Moral standards; Ethical consciousness; } \\
\text { Common good }\end{array}$ & S01, S05, S18, S40 \\
\hline \multicolumn{4}{|l|}{ Smart people } \\
\hline Developing e-skills & $\begin{array}{l}\text { It refers to enabling the development of digital skills by using } \\
\text { digital services. The substantial benefits provided by digital } \\
\text { services could encourage digital illiterates to learn how to use } \\
\text { them, while they continue to increase the knowledge of those } \\
\text { already digital literate }\end{array}$ & Citizen's self-development & $\begin{array}{l}\text { S01-S05, S07-S12, S15-S24, } \\
\text { S26, S29, S30-S33, S35, S37-S42 }\end{array}$ \\
\hline
\end{tabular}

taxonomy.

The values identified for type of service have been recognized and studied in various related work, as shown in Table 10. The level of maturity was based on well-defined existing classifications, as discussed in Section 5.2. The values identified for type of users, technologies and delivery channels were identified directly from the description of the surveyed services. No other values were added. The benefits were extracted from the description of the services. The criteria for classifying benefits was discussed among the authors, and the beneficiaries derived from the service descriptions. While some common functionality was extracted from the service descriptions, given the lack of detailed documentation, some other functionality was identified relying on related work (Douwe, Estevez, Ojo, \& Janowski, 2009; Estevez \& Janowski, 2007).

Finally, the focus group meetings enabled to validate the content of the taxonomy. In addition, many valuable ideas to improve the contributions of the taxonomy were recorded and will be considered for future work, including: 1) digitalization of the taxonomy and creation of an online platform where experts can contribute to the evolution of the taxonomy and documentation of case studies; 2) extension of the taxonomy with quantitative benefits, actions taken by the authorities to promote the use of the services, plans for training potential users, dissemination efforts, and information regarding service implementation, such as budget, schedules, staff, etc.; 3) identification of mobility services for people with disabilities, types of service providers, and services using social networks as delivery channel; and 4) categorization of users in terms of daily users such as commuters and students, and occasional users such as tourists.

\section{Maintenance}

The faceted structure provides flexibility to quickly extend the 
Table 8

Benefits and beneficiaries.

\begin{tabular}{|c|c|c|c|c|c|c|}
\hline ID & Benefits & TA & $\mathrm{D}$ & $\mathrm{P}$ & RO & $S$ \\
\hline B1 & Generating new sources of income & & $\mathrm{X}$ & & $\mathrm{X}$ & \\
\hline B2 & Generating personal savings & & $\mathrm{X}$ & $\mathrm{X}$ & $\mathrm{X}$ & \\
\hline B3 & Facilitating a sharing economy & & $\mathrm{X}$ & $\mathrm{X}$ & $\mathrm{X}$ & \\
\hline B4 & Resolving conflicts & & $\mathrm{X}$ & $\mathrm{X}$ & & \\
\hline B5 & Detecting illegal behaviour & $\mathrm{X}$ & $\mathrm{X}$ & & & $\mathrm{X}$ \\
\hline B6 & Facilitating journeys & & & $\mathrm{X}$ & & \\
\hline B7 & Reducing commuting time & & $\mathrm{X}$ & $\mathrm{X}$ & & \\
\hline B8 & Contributing to reducing traffic congestions & & $\mathrm{X}$ & $\mathrm{X}$ & & \\
\hline B9 & Facilitating seamless payment & & $\mathrm{X}$ & $\mathrm{X}$ & & \\
\hline B10 & Reducing $\mathrm{CO}_{2}$ emissions & & & & & $\mathrm{X}$ \\
\hline B11 & Contributing to becoming paperless society & & & & & $\mathrm{X}$ \\
\hline B12 & Using environmentally-friendly transport media & & & & & $\mathrm{X}$ \\
\hline B13 & Improving safety & & $\mathrm{X}$ & $\mathrm{X}$ & & $\mathrm{X}$ \\
\hline B14 & Improving quality of life & & $\mathrm{X}$ & $\mathrm{X}$ & & \\
\hline B15 & Reducing isolation & & & $\mathrm{X}$ & & \\
\hline B16 & Developing social values & & $\mathrm{X}$ & $\mathrm{X}$ & $\mathrm{X}$ & $\mathrm{X}$ \\
\hline B17 & Developing e-skills & $\mathrm{X}$ & $\mathrm{X}$ & $\mathrm{X}$ & $\mathrm{X}$ & $\mathrm{X}$ \\
\hline
\end{tabular}

$\mathrm{TA}=$ Transport Authority; $\mathrm{D}=$ Drivers; $\mathrm{P}=$ Passengers; $\mathrm{RO}=$ Resource Owners; $\mathrm{S}=$ Society.

taxonomy horizontally and vertically. New values can be added to each dimension as new initiatives are studied, and new dimensions can be explored as suggested in Section 6. Researchers in areas such as e-government, smart cities, and smart mobility are apt to maintain all dimensions except the common functionality dimension, which together with the technology and delivery channels dimensions, would be better maintained by researchers in software engineering and informatics. Below, we briefly discuss the maintainability of the existing dimensions.

Type of services: it could be extended both horizontally and vertically. A hierarchical structure could be suitable for further extending each category, e.g., parking services could be refined as parking sharing and parking search. As new trends and technology emerge, new types of mobility services can be explored, e.g., vehicle-to-vehicle communication services. Level of maturity: extensions will depend on innovative uses of ICT to deliver services, and can be extended as proposed in (Bertot et al., 2016). Types of users: it could be extended vertically and horizontally, following either a faceted or hierarchical structure. For example, a faceted structure will enable to distinguished passengers by periodicity (daily commuters, occasional passengers, and tourists) and by whether they possess some disability. A hierarchical structure will be more intuitive to separate drivers into motor-vehicle drivers and bicycle drivers. Technology: both sub-dimensions of technology could be extended vertically and horizontally using a hierarchical structure. For example, wireless, cabled and fiber could further refine the category Internet access; and further research following a conceptual to empirical approach could be conducted to identify types of smart sensors,

Driving guidance
Improving transport infrastructure
Locating objects
$=$ Monitoring transport
$=$ Payment
- Shared transport

- Improving transport resources

- Journey planner

Monitoring traffic

- Parking

- Reporting mobility

Traffic light optimization
Fig. 3. Type of service contributing to each identified benefit.

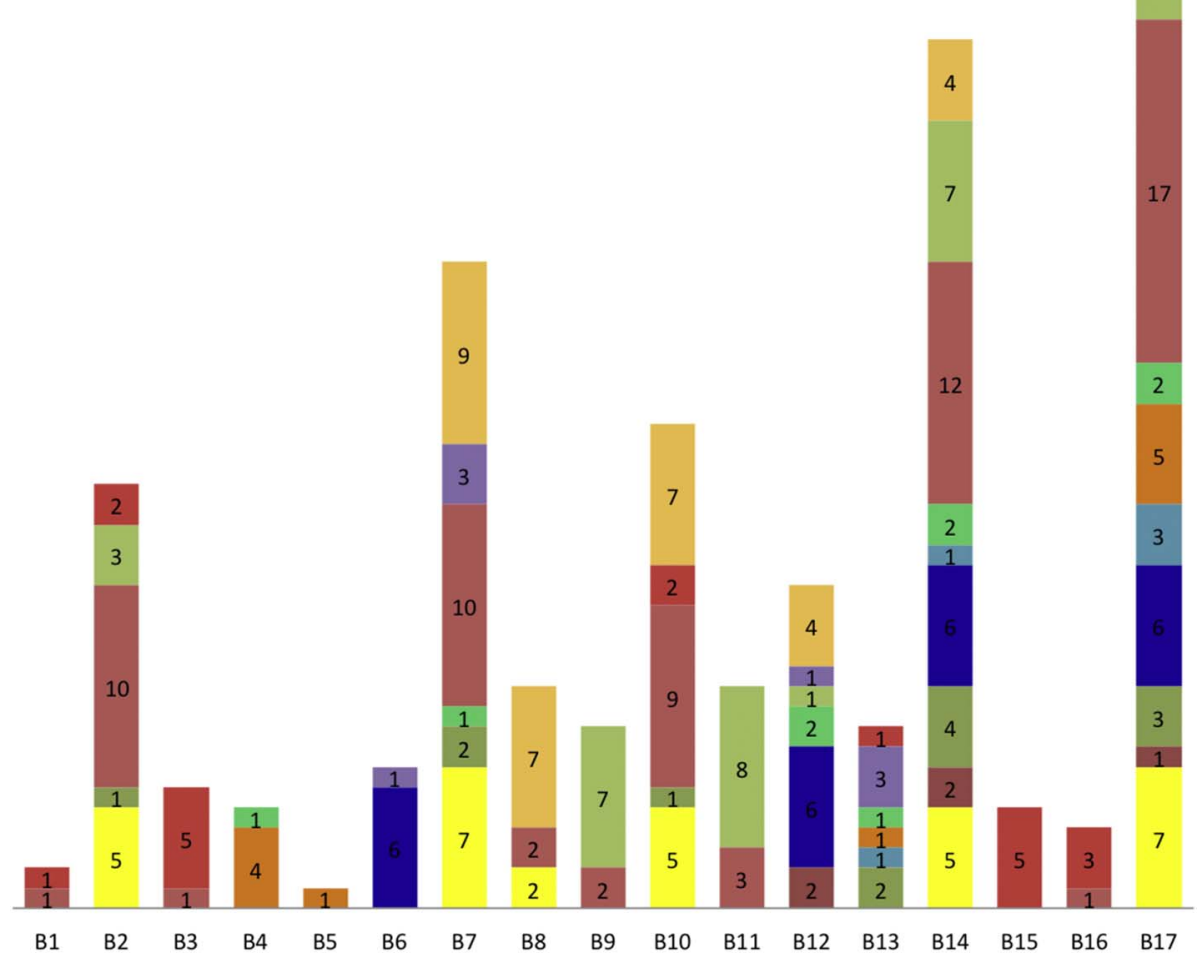




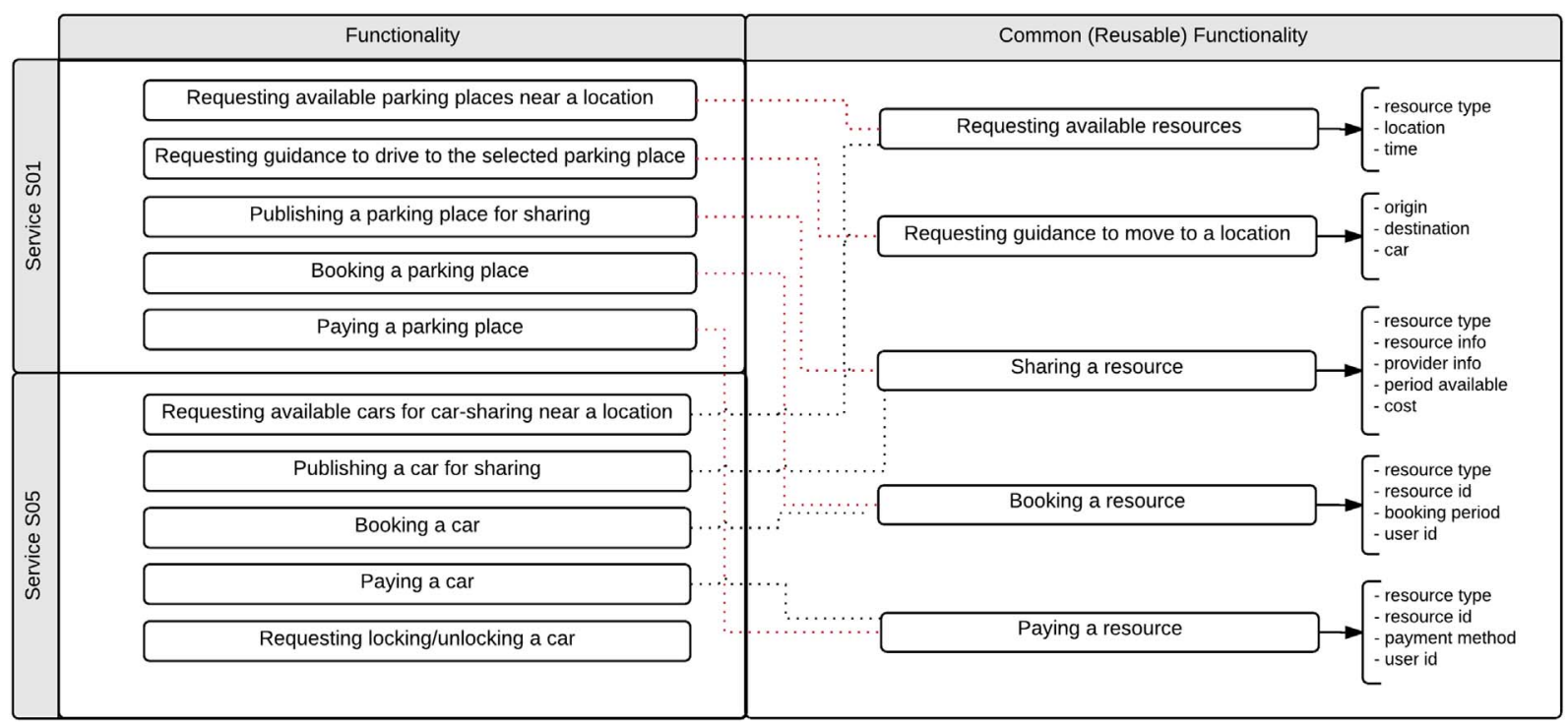

Fig. 4. Functionality and common functionality for two smart mobility services.

Table 9

Common functionality.

\begin{tabular}{|c|c|c|}
\hline Category & Description & Examples \\
\hline Requesting near resources & $\begin{array}{l}\text { It enables requesting and obtaining from a database all the resources of a given type that are located } \\
\text { near a given location }\end{array}$ & S07, S16, S21 \\
\hline $\begin{array}{l}\text { Requesting available nearby } \\
\text { resources }\end{array}$ & $\begin{array}{l}\text { It enables requesting and obtaining from a database all the resources of a given type that are located } \\
\text { near a given location and are available at a given timestamp }\end{array}$ & $\begin{array}{l}\text { S01, S02, S05, S07, S16, S17, S19, } \\
\text { S21, S29, S37, S41 }\end{array}$ \\
\hline $\begin{array}{l}\text { Requesting guidance to move to a } \\
\text { location }\end{array}$ & $\begin{array}{l}\text { It enables requesting and obtaining concrete instructions to move from a starting point to a } \\
\text { destination point by using one or more means of transportation specified. The guidance can be } \\
\text { provided with different levels of precision based on different factors, including distance and real time } \\
\text { traffic information, among others }\end{array}$ & $\begin{array}{l}\text { S01-S04, S07, S11, S16, S19, S21, } \\
\text { S38, S39 }\end{array}$ \\
\hline Calculating arrival time & $\begin{array}{l}\text { It calculates an estimated arrival time to reach a location from a starting point by using one or more } \\
\text { types of transport. The estimated time can have various levels of precision based on different factors, } \\
\text { such as distance, real time traffic information, public transport timetables, and geo-location } \\
\text { information of a vehicle }\end{array}$ & $\begin{array}{l}\text { S02, S03, S07, S11, S16, S18, S20, } \\
\text { S21, S38 }\end{array}$ \\
\hline $\begin{array}{l}\text { Calculating cost of a service or } \\
\text { resource }\end{array}$ & It calculates the cost of a service or the use of a resource, such as: a journey, a parking place, etc. & S07, S38 \\
\hline Sharing a resource & It enables specifying data about a transport-related resource that is offered to others & S01, S05, S18, S19, S40, S41 \\
\hline Booking a resource & It enables booking a transport-related resource for a given daytime & S01, S02, S05, S07, S19, S41 \\
\hline Paying a service & $\begin{array}{l}\text { It enables a payment transaction made by the user of a service or a resource to the service provider or } \\
\text { resource owner }\end{array}$ & $\begin{array}{l}\text { S01, S02, S05, S07, S12, S15, S19, } \\
\text { S20, S30, S36, }\end{array}$ \\
\hline $\begin{array}{l}\text { Locking and unlocking access to a } \\
\text { resource }\end{array}$ & $\begin{array}{l}\text { It enables the locking and unlocking of resources through non-traditional channels (non-manual) such } \\
\text { as mobile devices, RFID, etc. }\end{array}$ & S05, S07, S19 \\
\hline Requesting mobility records & It enables requesting and obtaining records of mobility services used or paid during a given period & S07, S15, s36 \\
\hline Locating a resource & It enables finding and showing the current location of an object in a map & $\begin{array}{l}\text { S01, S02, S05, S17, S21, S29, S35, } \\
\text { S37 }\end{array}$ \\
\hline
\end{tabular}

Table 10

Type of service - references from literature.

\begin{tabular}{|c|c|}
\hline Type of service & References \\
\hline Driving guidance & (Li, Wang, Zheng, \& Zhang, 2007; Yoo et al., 2008; Yuan et al., 2010) \\
\hline Improving transport resources & (Barrero, Mierlo, \& Tackoen, 2008; Fang \& Jianping, 2013; Yahiaoui, Khoudour, \& Meurie, 2010) \\
\hline Improving transport infrastructure & (Busold et al., 2013; Fazenda, Atmoko, Gu, Guan, \& Ball, 2009; Noei \& Sargolzaei, 2014) \\
\hline Journey planners & (Allulli, Italiano, \& Santaroni, 2014; Kostiainen, Erkut, \& Piella, 2011; Nelson \& Mulley, 2013) \\
\hline Locating objects & (Kung \& Vlah, 2003) \\
\hline Monitoring traffic & (Candamo, Shreve, Goldgof, Sapper, \& Kasturi, 2010; Kung \& Vlah, 2003; Semertzidis, Dimitropoulos, Koutsia, \& Grammalidis, 2010) \\
\hline Monitoring transport & (Harper, Fuller, Sweeney, \& Waldmann, 1998; Ladeira, Michel, \& Senna, 2011; Yang \& Zhang, 2014) \\
\hline Parking & (Arnott \& Inci, 2006; Nawaz, Efstratiou, \& Mascolo, 2013; Teodorović \& Lučić, 2006) \\
\hline Payment & (Blythe, 1999; Hinterwälder et al., 2013; Opiola \& Wilson, 2008) \\
\hline Reporting mobility & (Panichpapiboon \& Pattara-atikom, 2011; Sommer, Tonguz, \& Dressler, 2011; Wischhof, Ebner, \& Rohling, 2005) \\
\hline Sharing transport & (Firnkorn \& Müller, 2011; Prettenthaler \& Steininger, 1999; Santos, Behrendt, \& Teytelboym, 2010) \\
\hline Traffic light optimization & (Gora, 2011; Kareem \& Jantan, 2011; Sánchez, Galán, \& Rubio, 2008) \\
\hline
\end{tabular}


simulation algorithms, and video recognition techniques. Delivery Channel: it could be extended horizontally as new delivery channels are identified, such as social media. Benefits: it could be extended horizontally and vertically following a hierarchical approach, e.g., detecting illegal behaviour and resolving conflicts could be further refined by type of behaviour and conflict. Further benefits for each smart city dimension can be identified by further analysing smart mobility services. Beneficiaries: it can be adapted as new types of users are identified. Common functionality: it could be extended horizontally as smart mobility services are further analysed to identify similarities and variability.

\section{Discussion}

In this section, we discuss some challenges faced during the development process, approaches to overcome them and lessons learnt. We also provide usage scenarios of the taxonomy, and some recommendations for stakeholders involved in the development of smart mobility initiatives.

\subsection{Challenges and lessons learnt}

One main challenge faced was the difficulty in collecting relevant data about smart mobility services due to the lack of standardization and meaningful information provided, as well as a lack of comprehensive lists of initiatives in official government websites. In most cases, we conducted several searches involving different sources to have a clear picture about a given service. These makes it difficult for citizens, researchers and other governments to learn about initiatives and good practices implemented. In addition, it could affect the success of the services being delivered, since citizens may not be aware of their existence. In some cases, governments release reports about the initiatives, providing some organizational and strategic insights. Although these documents are good for other governments, usually they are unfriendly for citizens. Thus, some standardization and tradeoff is needed. Citizens would benefit from information about the available services, how they can use them, and how such usage benefits them. Government officials, researchers, and other stakeholders would benefit from information regarding planning, technical details and lessons learnt from smart mobility initiatives (un)successfully implemented. Moreover, access to such information could serve open government requirements, now being implemented at subnational level by the Open Government Partnership (OGP) ${ }^{16}$ In particular, the objectives of the OGP initiative include to "discover and promote new and innovative open government techniques and practices emerging at the subnational level around the world; and create practical opportunities for subnational governments to learn from each other, share experiences, and build upon the open government work of their counterparts".

During the data collection process, it was also difficult to find relevant information about the usage of the services. Only when services were delivered through a mobile application, some insights on the number of downloads, users' comments, and application rate was available from the application store. In many cases, the number of downloads was not representative with respect to city inhabitants, the rating was average, and there were significant number of complaints regarding the performance of the applications and the unattractiveness of user interfaces. Some recommendations to overcome this, is to have a dedicated strategy to ensure the efficient delivery and usage of smart mobility services. The strategy should strongly rely on citizen engagement, including, as a first step, conducting communication campaigns for promoting the services, informing citizens about their availability

\footnotetext{
$\mathbf{1 6}$ http://www.opengovpartnership.org/how-it-works/subnational-government-pilotprogram.
}

and benefits. Other steps should include initiatives for listening to citizens' feedback, facilitating user experimentation as part of innovation labs, documenting the level of user satisfaction, modifying services based on appropriate feedback, maintaining users informed about how their feedback is being used, ensuring the correct maintainability of the software, and collecting data about the actual usage of the services. These efforts should increase trust in the service and in the service provider, and enhance the level of acceptance and usage of the service.

In many cases, information about the stakeholders involved in the development and delivery of the services and about the level of government engagement was missing. Many of the services were provided by the public, as mechanisms for promoting a collaborative or sharing economy, e.g., most parking services were developed without government involvement. In all such cases, it is recommended that governments revise their roles as regulators and as providers of the needed platforms for promoting the development and delivery of such type of services by entrepreneurs and representatives of the private sector (Janssen \& Estevez, 2013).

Finally, since the data was collected, we noticed that some government websites have removed information about the services. The reasons could rely on several arguments, such as failure of the initiative, and closure after achieving its goals. To facilitate knowledge sharing, it would be helpful to maintain a knowledge base, accessible to the public, containing data and lessons learnt about conducted initiatives, whether they are active or not. This is important for other governments and researchers, but also for citizens, as accountability mechanism.

\subsection{Applications of the taxonomy}

Based on the challenges and lessons learnt, it would be interesting to have a conceptual framework for smart mobility services supporting standardized information, and enabling knowledge sharing about smart mobility initiatives. The taxonomy proposed here is a first step toward such a framework. It provides a common vocabulary to describe, discuss, and share information about smart mobility initiatives. Furthermore, the faceted structure enables different stakeholders to recover information in ways that betters suit their interests, e.g., recovering benefits or technology associated to a given type of service. In particular, we recognize three main potential users of the taxonomy: policy makers and government officials, IT staff, and researchers. Usage scenarios for each user are discussed below and summarized in Fig. 5.

Uses of the taxonomy by policy makers and government officials involved in the development of smart mobility initiatives include: 1) strategic planning and policy making - the taxonomy helps to identify stakeholders to whom services shall be delivered, to identify and illustrate different types of services to be delivered, and to identify corresponding benefits and beneficiaries, facilitating the justification of business cases for each initiative. For example, government practitioners motivated by a specific need can use the taxonomy to identify type of services that address those needs, benefits they provide, and functionality offered by the services. Conversely, given a type of service, government practitioners can use the taxonomy to understand the benefits that it delivers in order to convince different stakeholders involved to implement and use such a service; and 2) learning from others' experiences - the taxonomy facilitates standardize documentation of initiatives, as well as the creation of a catalogue of such initiatives, whether successful or not.

Uses of the taxonomy by IT staff, whether in government or not, include: 1) identifying families of public services - the taxonomy specifies common functionality that can be used to develop reusable components for smart mobility services. Furthermore, it can be used to study and identify families of service, i.e., services with a high level of similarities in their functionality but differing in some aspects. Families of services can then be developed following techniques from Software Product Line Engineering (SPLE), simplifying development efforts, improving service interoperability, and reducing service development 


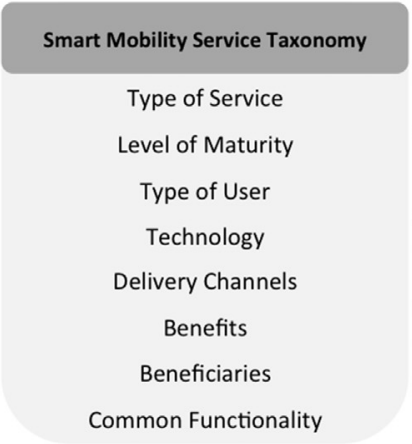

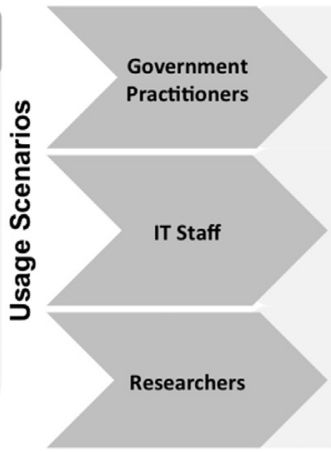

- Understanding and documenting smart mobility initiatives

- Sharing and discovering knowledge

- Strategic planning of smart mobility initiatives

- Formulating smart mobility policies

- Understanding smart mobility services

Identifying reusable components

Identifying user/public needs

Enabling innovations in smart mobility

- Building smart mobility services

- Understanding smart mobility services

Discovering research opportunities

- Contributing to the taxonomy

Fig. 5. Usage scenarios of the taxonomy.

time; 2) identifying innovation - the taxonomy can relate technologies used in different types of services. This is also useful to identify innovative uses of existing technology, which can serve to reduce costs.

Uses of the taxonomy by researchers include: 1) understanding the domain - the taxonomy provides a thorough view of different aspects of smart mobility services; and 2) development of new research lines researches can use the taxonomy for discovering research opportunities, e.g., by identifying new dimensions or by evolving existing dimensions based on new technology trends and innovations.

Finally, to take full advantage of the benefits discussed above we need an online knowledge base of smart mobility initiatives, with customizable searching tools, where each initiative is described using the dimensions and concepts proposed. In practice, it is challenging to achieve a unique global repository of initiatives. However, having a taxonomy that standardizes the domain, encourages various interested actors, mainly governments, in providing their own repositories. Thus, although information is not available in a unique place, it is consistent and structured, and facilitates (automatic) retrieval of information. In this sense, governments are considered the most interested stakeholders responsible for providing such online platforms.

\section{Conclusions}

We proposed a taxonomy of smart mobility services based on a state of the art review of mobility services in the context of smart cities. The taxonomy comprises eight dimensions: type of services, level of maturity, type of users, applied technologies, delivery channels, benefits, beneficiaries, and common functionality. For each dimension, we synthesized common concepts, provided definitions and illustrated them with the identified services.

The contribution of this work is twofold. First, it presents a broad mapping of mobility services that can be deployed in the context of smart city initiatives. Second, it introduces a taxonomy defining and classifying relevant concepts for policy makers and software engineers. On the one hand, policy makers can benefit from the taxonomy when defining smart mobility strategies, since it enables the identification of stakeholders to whom services need to be defined, exemplifies the different type of services to be delivered, and the corresponding benefits and beneficiaries, facilitating the justification of business cases for each initiative. In addition, entrepreneurs can benefit from the taxonomy to study possible market opportunities to innovate in the provision of smart mobility services. On the other hand, software engineers can benefit from the identification of common functionality that can be used to develop reusable components for smart mobility services. As a limitation, the analysis was based on secondary data. Such data was gathered from government websites and reporting documents as well as from scientific publications.

Future work includes extending the taxonomy based on the feedback received from domain experts, defining templates and instruments to facilitate smart mobility strategic planning processes based on the taxonomy dimensions, and specifying a software architecture for rapid development and deployment of smart mobility services based on the identified functionality.

\section{Acknowledgements}

This paper is a result of the project SmartEGOV: Harnessing EGOV for Smart Governance (Foundations, Methods, Tools) NORTE-01-0145FEDER-000037, supported by Norte Portugal Regional Operational Programme (NORTE 2020), under the PORTUGAL 2020 Partnership Agreement, through the European Regional Development Fund (EFDR). The first author is also supported by the Portuguese funding agency, FCT, under grant PD/BD/52238/2013.

\section{Appendix}

Table 11

State of practice references.

ID Service Summary Reference

S01 An application and website for parking: s1) share parking; s2) find available parking; s3) driving guidance; s4) booking and payment

S02 A platform for parking lorries: s1) find available parking, s2) booking; s2) driving guidance

S03 An application for driving guidance (particular drivers)

S04 An application for driving guidance (emergency vehicles) https://www.mobypark.com/en/parking-amsterdam-centre last visited on Oct 2014

http://amsterdamsmartcity.com/projects/detail/id/74/slug/thedigital-road-authority-air-quality last visited on Oct 2014

http://amsterdamsmartcity.com/projects/detail/id/75/slug/dedigitale-wegbeheerder-doorstroom-verkeer-ijburg last visited on Oct 2014

http://amsterdamsmartcity.com/projects/detail/id/76/slug/dedigitale-wegbeheerder-incident-management last visited on Oct 2014 
S05 A peer-to-peer car-sharing platform: s1) share cars; s2) find cars; s3) booking and payment; s4) lock and unlock cars' doors

S06 An energy saving tram that monitors different aspects of the journeys and takes proactive measures to increase passengers' comfort

S07 An application for multi-modal journeys: s1) journey planning; s2) booking and payment; s3) open doors (cars, parking); s4) mobility records

S08 Integrated system: s1) track assets; s2) real-time parking data; s3) traffic monitoring; s4) traffic light optimization; s5) dynamic pricing

S09 A system for studying traffic behaviour and optimize traffic light patterns

S10 An integrated system: s1) traffic light optimization; s2) detect parking places; s3) share information about transport; s4) dynamic lane size

S11 Multi-modal journey planner

S12 Payment of transport ticket through SMS

S13 A remote device for blind people to command traffic lights

S14 Faster green lights for emergency vehicles

S15 An application for paying street parking places

S16 A multi-modal journey planner

S17 SMS services to access information about public bicycles and cars sized by authorities

S18 An application to share taxi journeys

S19 An application and website for parking: s1) find available parking; s2) driving guidance; s3) booking and payment; s4) open parking doors

S20 Services for public buses: s1) on-board Wi-Fi; s2) payment; s3) realtime information; 4) monitor buses

S21 An online integrated itinerary for various types of buses

S22 Estimation of traveling times

S23 Traffic monitoring and traffic light optimization

S24 Integrated system: s1) f aster green lights for buses; s2) monitor buses

S25 Integrated system: s1) real-time traffic information; s2) dynamic message signs

S26 Traffic monitoring through CCTV

S27 Detection of vehicles' illegal behaviour through radars and CCTV

S28 Traffic light optimization by detecting congestions through RFID tags on cars

S29 A website for parking: s1) find available parking; S2) dynamic message signs

S30 Online payment of parking and traffic fines

S31 An online map with events that affect mobility

S32 Traffic monitoring, including detection of license plate numbers and estimations of traveling times

S33 Traffic light optimization and faster green lights for public transport

S34 Integrated system: s1) real-time traffic information; s2) dynamic message signs

S35 Online map with real-time traffic information and access to CCTV feeds

S36 A smart card for seamless payment of mobility services, including parking http://amsterdamsmartcity.com/projects/detail/id/2/slug/wegocar-sharing last visited on Oct 2014

https://smartcity.wien.at/site/en/projekte/verkehrstadtentwicklung/wiener-linien-schicken-energiespar-bim-auf-diestrecke/ last visited on Oct 2014

http://smile-einfachmobil.at/index_en.html last visited on Oct 2014

(City of Copenhagen, 2012a)

https://stateofgreen.com/en/profiles/city-of-copenhagen/solutions/ copenhagen-intelligent-traffic-solutions last visited on Oct 2014 https://stateofgreen.com/en/profiles/ramboll/solutions/its-

intelligent-transport-systems last visited on Oct 2014

(City of Copenhagen, 2012c).

(City of Copenhagen, 2012b)

http://smartcity.bcn.cat/es/semaforos-inteligentes.html last visited on Oct 2014

http://smartcity.bcn.cat/es/semaforos-inteligentes.html last visited on Oct 2014

http://apps4bcn.cat/esp/app/apparkb-1/373 last visited on Oct 2014

https://www.appandtown.com/going_with_you.html last visited on Oct 2014

http://w110.bcn.cat/portal/site/Mobil/menuitem. 39ee81df0abf91b0a042a042a2ef8a0c/?vgnextoid = 4ba9b04b2c7f4310VgnVCM10000074fea8c0RCRD\& vgnextchannel $=4$ ba9b04b2c7f4310VgnVCM10000074fea8c0RCRD \&lang $=$ ca_ES last visited on Oct 2014

http://www.joinuptaxi.com last visited on Oct 2014

https://barcelona.wesmartpark.com last visited on Oct 2014

(Ericsson, 2011)

http://www.urbs.curitiba.pr.gov.br/PORTAL/itinerarios/ last visited on Oct 2014

https://www.dataprom.com and http://www.setran.curitiba.pr.gov. $\mathrm{br} /$ servicos/fiscalizacao-eletronica last visited on Oct 2014

http://metro.co.uk/2012/01/09/songdo-in-south-korea-leadingcharge-to-become-city-of-the-future-279407/ last visited on Nov 2014

http://www.seattle.gov/transportation/epark/ last visited on Nov 2014

http://www.seattle.gov/courts/Ticket/ticketinformation.htm last visited on Nov 2014

http://web6.seattle.gov/SDOT/ConstructionMap/ last visited on Nov 2014

http://www.seattle.gov/transportation/its.htm last visited on Nov 2014

http://web6.seattle.gov/travelers/ last visited on Nov 2014

http://www.nol.ae/RtaPortal/Portal.portal?_nfpb = true\& _pageLabel $=$ home_learn_default\&lang $=$ en\&_nfls $=$ false last visited on Nov 2014 
S37 An application for finding taxis

S38 A multi-modal journey planner

S39 An application for finding available parking places and receive driving guidance

S40 An application for car-pooling

S41 A website for car-sharing

S42 An integrated centre: s1) traffic light optimization; s2) driving guidance for emergency vehicles; 3) analyse traffic behaviour
http://www.dsg.gov.ae/SiteCollectionImages/Content/

DeG\%20Documents/November-2013-en.pdf last visited on Nov 2014

http://wojhati.rta.ae/dub/XSLT_TRIP_REQUEST2?language = en last visited on Nov 2014

http://www.khaleejtimes.com/kt-article-display-1.asp?xfile = data/ transport/2014/September/transport_September16.xml\&section $=$ transport last visited on Nov 2014

http://www.surrey.ca/city-services/7071.aspx last visited on Nov 2014

http://www.surrey.ca/city-services/7071.aspx last visited on Nov 2014

http://www.surrey.ca/files/Smart_Surrey_Strategy_-_March_2015 WEB.pdf last visited on Nov 2014

\section{References}

Allulli, L., Italiano, G. F., \& Santaroni, F. (2014). Exploiting GPS data in public transport journey planners. 13th International Symposium on Experimental Algorithms.

Anastasi, G., Antonelli, M., Bechini, A., Brienza, S., Andrea, E. D., De Guglielmo, D., .. Lazzarino, L. L. (2013). Urban and social sensing for sustainable mobility in smart cities. 2013 Sustainable internet and ICT for sustainability, SustainIT 2013.

Arnott, R., \& Inci, E. (2006). An integrated model of downtown parking and traffic congestion. Journal of Urban Economics, 60(3), 418-442. http://dx.doi.org/10.1016/ j.jue.2006.04.004.

Bailey, K. D. (1994). Typologies and taxonomies: An introduction to classification techniques. Sage University paper series on quantitative applications in the social sciences, 07102http://dx.doi.org/10.1002/(SICI)1097-4571(199604)47:4<328::AID-ASI10 > 3. $0 . \mathrm{CO} ; 2-\mathrm{Y}$.

Bakillah, M., Liang, S. H. L., \& Zipf, A. (2012). Toward coupling sensor data and Volunteered Geographic Information (VGI) with agent-based transport simulation in the context of smart cities. GIS: Proceedings of the ACM international symposium on advances in geographic information systems (pp. 17-23).

Barrero, R., Van Mierlo, J., \& Tackoen, X. (2008). Enhanced energy storage systems for improved on-board light rail vehicle efficiency. IEEE Vehicular Technology Magazine, (September), 26-36. http://dx.doi.org/10.1109/MVT.2008.927485.

Benevolo, C., Dameri, R. P., \& Auria, B. D. (2016). Smart mobility in smart city - action taxonomy, ICT Intensity and Public Benefits, 11, 13-29. 10.1007/978-3-31923784-8.

Bertot, J., Estevez, E., \& Janowski, T. (2016). Universal and contextualized public services: Digital public service innovation framework. Government Information Quarterly, 33(2), 211-222. https://doi.org/10.1016/j.giq.2016.05.004.

Blythe, P. (1999). RFID for road tolling, road-use pricing and vehicle access control. IEE Colloquium (Digest) (pp. 67-82). . Retrieved from http://www.scopus.com/inward/ record.url? eid =2-s2.0-6344270248\&partnerID = tZOtx3y1.

Bruno, D., \& Richmond, H. (2003). The truth about taxonomies. Information Management Journal, 37(2), 44-53. Retrieved from http://www.freepatentsonline.com/article/ Information-Management-Journal/99236465.html.

Busold, C., Taha, A., Wachsmann, C., Dmitrienko, A., Seudié, H., Sobhani, M., \& Sadeghi, A.-R. (2013). Smart keys for cyber-cars: Secure smartphone-based NFC-enabled car immobilizer. Proceedings of the third ACM conference on data and application security and privacy (pp. 233-242). . http://dx.doi.org/10.1145/2435349.2435382.

Candamo, J., Shreve, M., Goldgof, D. B., Sapper, D. B., \& Kasturi, R. (2010). Understanding transit scenes: A survey on human behavior-recognition algorithms. IEEE Transactions on Intelligent Transportation Systems, 11(1), 206-224. http://dx.doi. org/10.1109/TITS.2009.2030963.

Cepolina, E. M., \& Farina, A. (2012). A new shared vehicle system for urban areas. Transportation Research Part C: Emerging Technologies, 21(1), 230-243. https://doi. org/10.1016/j.trc.2011.10.005.

Cisco, Susan L., \& Jackson, Wanda K. (2005). Creating order out of chaos with taxonomies. Information Management, 39(3), 44.

City of Copenhagen. (2012a). Copenhagen Connecting - An unique and innovative opportunity to shape the future of Copenhagen. Retrieved from http://itek.di.dk/ SiteCollectionDocuments/\%0DCopenhagenConnecting-UK_horizon2.pdf\%0D

City of Copenhagen. (2012b). Copenhagen Solutions for Sustainable Cities. Retrieved from kk.sites.itera.dk/apps/kk pub2/pdf/1353 58936BnEKE.pdf.

City of Copenhagen. (2012c). Integrated transport - The sustainable solution. Retrieved from www.cphcleantech.com

Deutsche Gesellschaft für Internationale Zusammenarbeit (2012). Urban transport and energy efficiency.

Djahel, S., Smith, N., Wang, S., \& Murphy, J. (2015). Reducing emergency services response time in smart cities: An advanced adaptive and fuzzy approach, (October).

Dobre, C., \& Xhafa, F. (2014). Intelligent services for Big Data science. Future Generation Computer Systems, 37, 267-281. https://doi.org/10.1016/j.future.2013.07.014.

Douwe, V., Estevez, E., Ojo, A., \& Janowski, T. (2009). Software infrastructure for egovernment - E-appointment service. Communications in Computer and Information Science, 62, 141-152. http://dx.doi.org/10.1007/978.

Ericsson. (2011). Mobile Broadband Making Brazil's Buses Better. Retrieved from https:// www.yumpu.com/en/document/view/19472881/mobile-broadband-makingbrazils-buses-better-ericsson

Estevez, E., \& Janowski, T. (2007). Building a dependable messaging infrastructure for electronic government. 2nd International Conference on Availability, Reliability and Security (pp. 948-955). ARES. http://dx.doi.org/10.1109/ARES.2007.53.

Fang, M., \& Jianping, C. (2013). A novel system for interactive mobile multimedia service in public transports. 867-870.

Fazenda, B., Atmoko, H., Gu, F. G. F., Guan, L. G. L., \& Ball, A. (2009). Acoustic based safety emergency vehicle detection for intelligent transport systems. 2009 Iccas-Sice, (1) (pp. 4250-4255). .

Firnkorn, J., \& Müller, M. (2011). What will be the environmental effects of new freefloating car-sharing systems? The case of car2go in Ulm. Ecological Economics, 70(8), 1519-1528. http://dx.doi.org/10.1016/j.ecolecon.2011.03.014.

Giffinger, R., Fertner, C., Kramar, H., Kalasek, R., Pichler-Milanović, N., \& Meijers, E. (2007). Smart cities Ranking of European medium-sized cities. October, 16(October), 13-18. http://dx.doi.org/10.1016/S0264-2751(98)00050-X.

Gora, P. (2011). A genetic algorithm approach to optimization of vehicular traffic in cities by means of configuring traffic lights. Studies in Computational Intelligence, 369, 1-10. http://dx.doi.org/10.1007/978-3-642-22732-5_1.

Gora, P., \& Wasilewski, P. (2014). Adaptive system for intelligent traffic management in smart cities. In D. Ślęzak, G. Schaefer, S. Vuong, \& Y.-S. Kim (Vol. Eds.), Active media technology SE - 44. Vol. 8610. Active media technology SE - 44 (pp. 525-536). Springer International Publishing. http://dx.doi.org/10.1007/978-3-319-09912-5_44.

Harper, J. G., Fuller, R., Sweeney, D., \& Waldmann, T. (1998). Human factors in technology replacement: A case study in interface design for a public transport monitoring system. Applied Ergonomics, 29(2), 133-146.

Hinterwälder, G., Zenger, C. T., Baldimtsi, F., Lysyanskaya, A., Paar, C., \& Burleson, W. P. (2013). Efficient e-cash in practice: NFC-based payments for public transportation systems. Lecture Notes in Computer Science (Including Subseries Lecture Notes in Artificial Intelligence and Lecture Notes in Bioinformatics), 40-59. 7981 LNCS https://doi.org/10. 1007/978-3-642-39077-73.

Horng, G.-J., Li, J.-P., \& Cheng, S.-T. (2013). Traffic congestion reduce mechanism by adaptive road routing recommendation in smart city. 2013 3rd international conference on consumer electronics, communications and networks (pp. 714-717). . http:// dx.doi.org/10.1109/CECNet.2013.6703431.

Janowski, T. (2015). Digital government evolution: From transformation to contextualization. Government Information Quarterly, 32(3), 221-236. http://dx.doi.org/ 10.1016/j.giq.2015.07.001.

Janowski, T. (2016). Implementing sustainable development goals with digital government - Aspiration-capacity gap. Government Information Quarterly, 33(4), 603-613. http://dx.doi.org/10.1016/j.giq.2016.12.001.

Janssen, M., \& Estevez, E. (2013). Lean government and platform-based governance doing more with less. Government Information Quarterly, 30(1), S1-S8. http://dx.doi. org/10.1016/j.giq.2012.11.003.

Ji, Z., Ganchev, I., O'Droma, M., Zhao, L., \& Zhang, X. (2014). A cloud-based car parking middleware for IoT-based smart cities: Design and implementation. Sensors (Basel, Switzerland), 14(12), 22372-22393. https://doi.org/10.3390/s141222372.

Jørgensen, T. B., \& Bozeman, B. (2007). Public values - An inventory. Adminsitration \& Society, 39(3), 354-381. http://dx.doi.org/10.1177/0095399707300703.

Kareem, E. I. A., \& Jantan, A. (2011). An intelligent traffic light monitor system using an adaptive associative memory. International Journal of Information Processing and Management, 2(2), 23-39. http://dx.doi.org/10.4156/ijipm.vol2.issue2.4.

Kostiainen, J., Erkut, C., \& Piella, F. B. (2011). Design of an audio-based mobile journey planner application. Proceedings of the 15th International Academic MindTrek Conference on Envisioning Future Media Environments - MindTrek '11, 107. https:// doi.org/10.1145/2181037.2181056.

Kung, H. T., \& Vlah, D. (2003). Efficient location tracking using sensor networks. IEEE Wireless Communications and Networking WCNC 2003. Vol. 3http://dx.doi.org/10. 1109/WCNC.2003.1200686.

Kwasnik, B. H. (1999). The role of classification in knowledge representation and discovery. Library Trends, 48(1), 22-47.

Ladeira, M., Michel, F., \& Senna, L. (2011). Public transport monitoring and control: The case of Porto Alegre, Brazil. ICTIS, 2011, 275-281. http://dx.doi.org/10.1061/ 41177(415)35. 
Layne, K., \& Lee, J. (2001). Developing fully functional E-government: A four stage model. Government Information Quarterly, 18(2), 122-136. http://dx.doi.org/10. 1016/S0740-624X(01)00066-1.

Li, L., Wang, F.-Y., Zheng, N.-N., \& Zhang, Y. (2007). Research and developments of intelligent driving behaviour analysis. Zidonghua Xuebao/Acta Automatica Sinica. http://dx.doi.org/10.1360/aas.

Mallus, M., Colistra, G., Atzori, L., Murroni, M., \& Pilloni, V. (2017). Dynamic carpooling in urban areas: Design and experimentation with a multi-objective route matching algorithm. Sustainability (Switzerland), 9(2), http://dx.doi.org/10.3390/su9020254.

Morris, E.a. (2015). Should we all just stay home? Travel, out-of-home activities, and life satisfaction. Transportation Research Part A: Policy and Practice, 78, 519-536. http:// dx.doi.org/10.1016/j.tra.2015.06.009.

Motta, G., Sacco, D., Belloni, A., \& You, L. (2013). A system for green personal integrated mobility. Proceedings of 2013 IEEE International Conference on Service Operations and Logistics, and Informatics, SOLI 2013.

Motta, G., You, L., Sacco, D., \& Miceli, G. (2014). Mobility service systems: Guidelines for a possible paradigm and a case study. Proceedings of 2014 IEEE International Conference on Service Operations and Logistics, and Informatics, SOLI 2014 (pp. 4853). .

Nawaz, S., Efstratiou, C., \& Mascolo, C. (2013). ParkSense: A smartphone based sensing system for on-street parking. Proceedings of the 19th Annual International Conference on Mobile Computing and Networking - Mobicom '13. Retrieved from http://dl.acm.org/ citation.cfm? $\mathrm{id}=2500438$.

Neirotti, P., De Marco, A., Cagliano, A. C., Mangano, G., \& Scorrano, F. (2014). Current trends in Smart City initiatives: Some stylised facts. Cities, 38, 25-36. http://dx.doi. org/10.1016/j.cities.2013.12.010.

Nelson, J. D., \& Mulley, C. (2013). The impact of the application of new technology on public transport service provision and the passenger experience: A focus on implementation in Australia. Research in Transportation Economics, 39(1), 300-308 http://dx.doi.org/10.1016/j.retrec.2012.06.028.

Nickerson, R. C., Varshney, U., \& Muntermann, J. (2012). A method for taxonomy development and its application in information systems. European Journal of Information Systems, 22(3), 336-359. http://dx.doi.org/10.1057/ejis.2012.26.

Noei, S., \& Sargolzaei, A. (2014). Reducing traffic congestion using geo-fence technology: Application for emergency car. 15-20.

Opiola, J., \& Wilson, S. (2008). Bank payments in transportation - freedom and interoperability for congestion pricing. 15th World Congress on Intelligent Transport Systems and ITS America Annual Meeting 2008. Vol. 2. 15th World Congress on Intelligent Transport Systems and ITS America Annual Meeting 2008 (pp. 1303-1318). . Retrieved from http://www.scopus.com/inward/record.url?eid=2-s2.0-84879012282\& partnerID $=$ tZOtx3y1.

Panichpapiboon, S., \& Pattara-atikom, W. (2011). A review of information dissemination protocols for vehicular ad hoc networks. IEEE Communications Surveys \& Tutorials, 14(3), 784-798. http://dx.doi.org/10.1109/SURV.2011.070711.00131.

Perboli, G., De Marco, A., Perfetti, F., \& Marone, M. (2014). A new taxonomy of smart city projects. Transportation Research Procedia, 3(July), 470-478. http://dx.doi.org/10. 1016/j.trpro.2014.10.028.

Pokriü, B., Krbo, S., \& Pokriü, M. (2015). Augmented reality based Smart City services using secure IoT infrastructure. Proceedings - 2014 IEEE 28th International Conference on Advanced Information Networking and Applications Workshops, IEEE WAINA 2014http://dx.doi.org/10.1109/WAINA.2014.127.

Prettenthaler, F. E., \& Steininger, K. W. (1999). From ownership to service use lifestyle. Ecological Economics, 28(3), 443-453. http://dx.doi.org/10.1016/S0921-8009(98) 00109-8.

Sánchez, J., Galán, M., \& Rubio, E. (2008). Applying a traffic lights evolutionary optimization technique to a real case: "Las Ramblas" area in Santa Cruz de Tenerife. IEEE Transactions on Evolutionary Computation, 12(1), 25-40. http://dx.doi.org/10.1109/ TEVC. 2007.892765.

Santos, G., Behrendt, H., \& Teytelboym, A. (2010). Part II: Policy instruments for sustainable road transport. Research in Transportation Economics, 28(1), 46-91. http:// dx.doi.org/10.1016/j.retrec.2010.03.002.

Schnitzler, F., Artikis, A., Weidlich, M., Boutsis, I., Liebig, T., Piatkowski, N., ... Gunopulos, D. (2014). Heterogeneous stream processing and crowdsourcing for traffic monitoring: Highlights. In T. Calders, F. Esposito, E. Hüllermeier, \& R. Meo (Vol. Eds.), Machine learning and knowledge discovery in databases SE - 49. Vol. 8726. Machine learning and knowledge discovery in databases SE - 49 (pp. 520-523). Berlin Heidelberg: Springer. http://dx.doi.org/10.1007/978-3-662-44845-8_49.

Semertzidis, T., Dimitropoulos, K., Koutsia, A., \& Grammalidis, N. (2010). Video sensor network for real-time traffic monitoring and surveillance. IET Intelligent Transport Systems, 4(2), 103. http://dx.doi.org/10.1049/iet-its.2008.0092.

Seredynski, M., Ruiz, P., Szczypiorski, K., \& Khadraoui, D. (2014). Improving bus ride comfort using GLOSA-based dynamic speed optimisation. Proceedings of the
International Parallel and Distributed Processing SymposiumIPDPShttp://dx.doi.org/10. 1109/IPDPSW.2014.58.

Sommer, C., Tonguz, O. K., \& Dressler, F. (2011). Traffic information systems: Efficient message dissemination via adaptive beaconing. IEEE Communications Magazine, 49(5), 173-179. http://dx.doi.org/10.1109/MCOM.2011.5762815.

Stolfi, D. H., \& Alba, E. (2014). Red swarm: Reducing travel times in smart cities by using bio-inspired algorithms. Applied Soft Computing Journal, 24, 181-195. http://dx.doi. org/10.1016/j.asoc.2014.07.014.

Suzumura, T., Kato, S., Imamichi, T., Takeuchi, M., Kanezashi, H., Ide, T., \& Onodera, T. (2012). X10-based massive parallel large-scale traffic flow simulation. Proceedings of the ACM SIGPLAN 2012 X10 Workshop on - X10 '12 (pp. 1-4). . http://dx.doi.org/10. $1145 / 2246056.2246059$.

Szabo, R., Farkas, K., Ispany, M., Benczur, A. A., Batfai, N., Jeszenszky, P., ... Feher, G. (2013). Framework for smart city applications based on participatory sensing. Cognitive Infocommunications (CogInfoCom), 2013 IEEE 4th international conference on (pp. 295-300). . http://dx.doi.org/10.1109/CogInfoCom.2013.6719260.

Tarapiah, S., Atalla, S., Autonomo, L., \& Alsayid, B. (2014). Smart on-board transportation management system geo-casting featured. 2014 World Congress on Computer Applications and Information Systems, WCCAIS 2014.

Teodorović, D., \& Lučić, P. (2006). Intelligent parking systems. European Journal of Operational Research, 175(3), 1666-1681. http://dx.doi.org/10.1016/j.ejor.2005.02. 033.

U.S. Environmental Protection Agency (2015). Inventory of U.S. greenhouse gas emissions and sinks: 1990-2013. Retrieved from http://www.epa.gov/climatechange/ Downloads/ghgemissions/US-GHG-Inventory-2015-Main-Text.pdf.

UNEP (2012). Sustainable, resource efficient cities - Making it happen!. United Nations Environment Proggramme.

United Nations (2014). World urbanization prospects: The 2014 revision, highlights. New York, United. http://dx.doi.org/10.4054/DemRes.2005.12.9.

Wischhof, L., Ebner, A., \& Rohling, H. (2005). Information dissemination in self-organizing intervehicle networks. IEEE Transactions on Intelligent Transportation Systems, 6(1), 90-101. http://dx.doi.org/10.1109/TITS.2004.842407.

Yahiaoui, T., Khoudour, L., \& Meurie, C. (2010). Real-time passenger counting in buses using dense stereovision. Journal of Electronic Imaging, 19(3), 31202. http://dx.doi. org/10.1117/1.3455989.

Yang, X., \& Zhang, L. (2014). A dynamic method to monitor public transport based on. 17th International Conference on Intelligent Transportation Systems (ITSC) (pp. 924929).

Yaqoob, I., Hashem, I. A. T., Mehmood, Y., Gani, A., Mokhtar, S., \& Guizani, S. (2017). Enabling communication technologies for smart cities. IEEE Communications Magazine, 55(1), 112-120. http://dx.doi.org/10.1109/MCOM.2017.1600232CM.

Yoo, S. E., Chong, P. K., Park, T., Kim, Y., Kim, D., Shin, C., ... Kim, H. (2008). DGS: Driving guidance system based on wireless sensor network. Proceedings - international conference on advanced information networking and applications, AINA (pp. 628-633). . http://dx.doi.org/10.1109/WAINA.2008.184.

Yuan, J., Zheng, Y., Zhang, C., Xie, W., Xie, X., Sun, G., \& Huang, Y. (2010). T-drive: Driving directions based on taxi trajectories. Proceedings of the 18th SIGSPATIAL International Conference on Advances in Geographic Information Systems - GIS '10, (2010) (pp. 99). . http://dx.doi.org/10.1145/1869790.1869807.

Guillermina Cledou is a full-time PhD student at the MAP-i Doctoral Program in Computer Science held by the Universities of Minho, Porto and Aveiro, Portugal. The title of her PhD thesis is "A Virtual Factory for Smart City Service Integration". She has a Licenciado degree in Computer Science from Universidad Nacional del Sur, Argentina.

Elsa Estevez is an Adjunct Professor at Universidad National del Sur and Independent Researcher at the National Scientific and Technical Research Council (CONICET) in Argentina. Previously, she was Senior Academic Programme Officer at the United Nations University Operating Unit on Policy-Driven Electronic Governance (UNU-EGOV), located in Guimarães, Portugal; Academic Programme Officer at the UNU International Institute for Software Technology in Macao, China; visiting professor in three universities in Argentina; and head of information technology departments in major financial and pharmaceutical organizations in Argentina.

Luís Soares Barbosa is an Associate Professor with Habilitation at the Department of Informatics at the University of Minho, Deputy Head of UNU-EGOV, United Nations University, and a senior researcher at the High Assurance Software Laboratory at INESC TEC - a research laboratory rated "Excellent" in the latest National Research Assessment. His research interests include models for computational systems and calculi applied to rigorous software construction. 